\title{
Evaluation of CLaMS, KASIMA and ECHAM5/MESSy1 simulations in the lower stratosphere using observations of Odin/SMR and ILAS/ILAS-II
}

\author{
F. Khosrawi ${ }^{1, *}$, R. Müller ${ }^{1}$, M. H. Proffitt ${ }^{2}$, R. Ruhnke ${ }^{3}$, O. Kirner ${ }^{3}$, P. Jöckel ${ }^{4}$, J.-U. Grooß ${ }^{1}$, J. Urban ${ }^{5}$, D. Murtagh ${ }^{5}$, \\ and H. Nakajima ${ }^{6}$ \\ ${ }^{1}$ ICG-1, Forschungszentrum Jülich, 52425 Jülich, Germany \\ ${ }^{2}$ Proffitt Instruments, 1109 Havre Lafitte Drive, Austin, Texas 78746, USA \\ ${ }^{3}$ IMK, Forschungszentrum Karlsruhe, 76021 Karlsruhe, Germany \\ ${ }^{4}$ MPI for Chemistry, 55128 Mainz, Germany \\ ${ }^{5}$ Department of Radio and Space Science, Chalmers University of Technology, 41296 Göteborg, Sweden \\ ${ }^{6}$ NIES, Tsukuba, Ibaraki, 305-8506 Japan \\ *now at: MISU, Stockholm University, 10691 Stockholm, Sweden
}

Received: 15 October 2008 - Published in Atmos. Chem. Phys. Discuss.: 22 January 2009

Revised: 15 July 2009 - Accepted: 4 August 2009 - Published: 12 August 2009

\begin{abstract}
. 1-year data sets of monthly averaged nitrous oxide $\left(\mathrm{N}_{2} \mathrm{O}\right)$ and ozone $\left(\mathrm{O}_{3}\right)$ derived from satellite measurements were used as a tool for the evaluation of atmospheric photochemical models. Two 1-year data sets, one solar occultation data set derived from the Improved Limb Atmospheric Spectrometer (ILAS and ILAS-II) and one limb sounding data set derived from the Odin Sub-Millimetre Radiometer (Odin/SMR) were employed. Here, these data sets are used for the evaluation of two Chemical Transport Models (CTMs), the Karlsruhe Simulation Model of the Middle Atmosphere (KASIMA) and the Chemical Lagrangian Model of the Stratosphere (CLaMS) as well as for one ChemistryClimate Model (CCM), the atmospheric chemistry general circulation model ECHAM5/MESSy1 (E5M1) in the lower stratosphere with focus on the Northern Hemisphere. Since the Odin/SMR measurements cover the entire hemisphere, the evaluation is performed for the entire hemisphere as well as for the low latitudes, midlatitudes and high latitudes using the Odin/SMR 1-year data set as reference. To assess the impact of using different data sets for such an evaluation study we repeat the evaluation for the polar lower stratosphere using the ILAS/ILAS-II data set. Only small differences were found using ILAS/ILAS-II instead of Odin/SMR as a reference, thus, showing that the results are not influenced by the particular satellite data set used for the evaluation. The evalu-
\end{abstract}

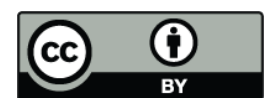

Correspondence to: F. Khosrawi (farah@misu.su.se) ation of CLaMS, KASIMA and E5M1 shows that all models are in agreement with Odin/SMR and ILAS/ILAS-II. Differences are generally in the range of $\pm 20 \%$. Larger differences (up to $-40 \%$ ) are found in all models at $500 \pm 25 \mathrm{~K}$ for $\mathrm{N}_{2} \mathrm{O}$ mixing ratios greater than $200 \mathrm{ppbv}$, thus in air masses of tropical character. Generally, the largest differences were found for the tropics and the lowest for the polar regions. However, an underestimation of polar winter ozone loss was found both in KASIMA and E5M1 both in the Northern and Southern Hemisphere.

\section{Introduction}

The slowly decreasing level of halogens in the stratosphere in the coming decades is expected to lead to a gradual recovery from the chemical ozone depletion that is clearly noticeable in the extratropics since $\sim 1980$ (WMO, 2007). However, in the future the stratosphere will be influenced by a range of processes (radiative, dynamical and chemical) resulting from increases in green-house gas concentrations and future IPCC reports will be based on climate models that include full representation of the stratosphere (Shaw and Shepherd, 2008). Therefore, an improved understanding of these processes as well as the interaction between chemistry and climate is needed if credible predictions of future levels of stratospheric ozone and its impact on climate and surface UV radiation are to be made (WMO, 2007; Eyring et al., 2006, 2007). A number of Chemistry-Climate Models (CCMs)

Published by Copernicus Publications on behalf of the European Geosciences Union. 
have been developed in the recent decade in order to provide such predictions. Although a lot of progress has been made the prediction of current CCMs produce still a wide range of results concerning the timing and extent of the ozone layer recovery (WMO, 2007). Analyses of chemical ozone loss in the polar regions in CCM simulations show a substantial underestimation of ozone loss in the Antarctic and a severe underestimation of ozone loss in the Arctic (Lemmen et al., 2006; Tilmes et al., 2007). Further, Hegglin and Shepherd (2007) showed that the variability of Arctic polar ozone loss is underestimated in the Canadian Middle Atmosphere Model (CMAM). Therefore, evaluating these models with measurements, using a variety of diagnostics and ensuring that appropriate diagnostics are used, is essential (Eyring et al., 2006; Müller et al., 2008).

Here, we use a method based on ozone $\left(\mathrm{O}_{3}\right)$ and nitrous oxide $\left(\mathrm{N}_{2} \mathrm{O}\right)$ measurements to evaluate Chemical Transport Models (CTMs) as well as Chemistry Climate Models (CCMs) in the lower stratosphere. In this method, monthly averages of the $\mathrm{O}_{3} / \mathrm{N}_{2} \mathrm{O}$ correlation binned by potential temperature are calculated. This method was introduced by Proffitt et al. (2003) for the Northern Hemisphere lower stratosphere based on aircraft and balloon-borne measurements. In their study, Proffitt et al. (2003) consider seasonally averaged lower stratospheric distributions of $\mathrm{N}_{2} \mathrm{O}$ and $\mathrm{O}_{3}$ which were binned by potential temperature or altitude. The study of Proffitt et al. (2003) was based on high altitude aircraft (ER-2) data obtained from 139 flights and 12 profiles derived from balloon measurements, and was restricted to the lower stratosphere and the Northern Hemisphere. The method of Proffitt et al. (2003) has then been extended to greater altitudes and to the Southern Hemisphere by Khosrawi et al. $(2004,2006)$ using satellite data from the Improved Limb Atmospheric Spectrometers (ILAS and ILAS-II). However, the ILAS/ILAS-II data are restricted to the polar regions. In a follow-up study by Khosrawi et al. (2008) satellite data from the Odin/Sub Millimetre Radiometer (Odin/SMR) were used which allowed an extension of the method to the entire Northern and Southern Hemisphere as well as a separation into polar, midlatitude and tropical regimes. A comparison of the ILAS/ILAS-II and Odin/SMR data sets in the polar regions showed that both data sets can be used for the evaluation of CTMs and CCMs. Thus, in Khosrawi et al. (2008) we could verify the ILAS/ILAS-II 1year data set and demonstrate that limited sampling of a solar occultation instrument such as ILAS/ILAS-II does not constitute a problem in deriving such a data set of monthly averages of $\mathrm{N}_{2} \mathrm{O}$ and $\mathrm{O}_{3}$. However, both in Khosrawi et al. (2008) and in the present study the focus is on the lower stratosphere. The applicability of the method for model evaluation in the upper stratosphere has so far not been tested but will be a matter of future research.

It is important to distinguish between the method of Proffitt et al. (2003) which is used in the present study and the ozone-tracer relations in the classical sense (e.g.,
Proffitt et al., 1993; Müller et al., 1996; Tilmes et al., 2004). Tracer-tracer relationships between long-lived chemical species such as $\mathrm{N}_{2} \mathrm{O}$ and ozone $\mathrm{O}_{3}$ have been used for several decades to analyze stratospheric data (e.g., Proffitt et al., 1990). In general, long-lived tracers exhibit compact, robust relationships in the stratosphere which eliminate short term fluctuations from tracer data sets (Plumb and Ko, 1992; Plumb, 2007; Hegglin and Shepherd, 2007). An almost linear relationship of ozone-tracer and $\mathrm{NO}_{y}$-tracer correlations exists in the high-latitude wintertime lower stratosphere (Plumb and Ko, 1992). Deviations from such canonical relationships are used to identify chemical and physical processes such as dehydration and denitrification (e.g., Kelly et al., 1989; Fahey et al., 1990; Rex et al., 1999) and ozone loss (e.g., Proffitt et al., 1989a, 1990; Müller et al., 1996; Salawitch et al., 2002; Tilmes et al., 2004, 2006) in the Northern and Southern Hemispheric polar regions. $\mathrm{O}_{3}$ tracer correlations in the classical sense are designed to eliminate diabatic descent from the analysis which (among other things) requires the correlations to remain compact. For the method put forward by Proffitt et al. (2003), in contrast, diabatic descent is important whereas compactness of the correlations is much less relevant. Hegglin and Shepherd (2007) proposed a further technique for using $\mathrm{O}_{3}-\mathrm{N}_{2} \mathrm{O}$ correlations to evaluate model results, namely, deriving equal area twodimensional Probability Density Functions (PDFs) of $\mathrm{O}_{3}^{-}$ $\mathrm{N}_{2} \mathrm{O}$ pairs. They applied this technique based on Atmospheric Chemistry Experiment (ACE-FTS) data to evaluate the aspects of transport and polar ozone loss in CMAM. Conversely, they used CMAM to assess sampling artefacts of the ACE-FTS (solar occultation) measurements. They found that this method is useful to avoid sampling biases as they might occur when solar occultation measurements and thus tracer distributions with an uneven geographical coverage are used. The Odin/SMR data which are used here for the model evaluation are derived from limb sounding measurements that provide much better geographical coverage than data from solar occultation instruments.

Here, we apply the method of Proffitt et al. (2003) to 1 -year data sets derived from Odin/SMR and ILAS/ILASII to evaluate simulations in the lower stratosphere of two CTMs, namely the Chemical Lagrangian Model of the Stratosphere (CLaMS) and the Karlsruhe Simulation Model of the Middle Atmosphere (KASIMA) as well as one CCM, the atmospheric chemistry general circulation model ECHAM5/MESSy1 (E5M1). Since the Odin/SMR measurements cover the entire hemisphere, the evaluation is performed for the entire hemisphere as well as for the low latitudes, midlatitudes and high latitudes using the Odin/SMR 1 -year data set as reference. To assess the impact of using different data sets for such an evaluation study we repeat the evaluation for the polar lower stratosphere using the ILAS/ILAS-II data set. In general, we find an agreement between Odin/SMR and ILAS/ILAS-II data, respectively, with model results from CLaMS, KASIMA and E5M1. 


\section{Model data}

\subsection{CLaMS}

The Chemical Lagrangian Model of the Stratosphere (CLaMS) is a chemistry transport model which simulates the dynamics and chemistry of multiple air parcels along their trajectories (McKenna et al., 2002a,b; Konopka et al., 2004). The trajectories are determined from wind fields taken from European Centre for Medium-Range Weather Forecasts (ECMWF) operational analyses. The mixing of air parcels, that is the interaction between neighboring air parcels, is introduced both by combining air parcels and adding new air parcels where the mixing intensity is driven by the deformation of the wind field (McKenna et al., 2002a). As the air parcels are distributed irregularly in space, the horizontal resolution is defined by the mean distance of neighboring air parcels on an isentropic surface. Vertical motion is calculated as the time derivative of potential temperature using the radiation scheme by Morcrette (1991). Here, we used a CLaMS simulation for the Northern Hemisphere with a horizontal resolution of $100 \mathrm{~km}$ north $40^{\circ} \mathrm{N}$ and of $300 \mathrm{~km}$ between $40^{\circ} \mathrm{N}$ and the equator (Grooß et al., 2005). As vertical coordinate potential temperature is used, divided into 30 equally spaced levels between 350 and $900 \mathrm{~K}$. The CLaMS simulation used here started on 17 November 2002 and was run until 23 March 2003. The initialization of $\mathrm{O}_{3}$ was based on the MIPAS/ENVISAT data from 16 and 17 November 2002. A detailed description of the CLaMS model and this simulation can be found in McKenna et al. (2002a,b), Konopka et al. (2004) and Grooß et al. (2005).

\subsection{KASIMA}

The Karlsruhe Simulation Model of the Middle Atmosphere (KASIMA) is a mechanistical circulation model including stratospheric chemistry for the simulation of the behavior of physical and chemical processes in the middle atmosphere (Ruhnke et al., 1999; Reddmann et al., 2001). The meteorological component is based on a spectral architecture with the pressure altitude $z=-H \cdot \ln \left(p / p_{0}\right)$ as vertical coordinate where $H=7 \mathrm{~km}$ is a constant atmospheric scale height, $p$ is the pressure, and $p_{0}=1013.25 \mathrm{hPa}$ is a constant reference pressure. A horizontal resolution of T42 $\left(2.8^{\circ} \times 2.8^{\circ}\right)$ has been used. In the vertical regime, 63 levels between 10 and $120 \mathrm{~km}$ pressure altitude and a $0.75 \mathrm{~km}$ spacing from $10 \mathrm{up}$ to $22 \mathrm{~km}$ with an exponential increase above were used. The meteorology module of the KASIMA model consists of three versions: the diagnostic model, the prognostic model and the nudged model which combines the prognostic and diagnostic model (Kouker et al., 1999). In this study, the model is nudged towards the operational ECMWF analyses of temperature, vorticity and divergence between 7 and $48 \mathrm{~km}$ pressure altitude. Above $48 \mathrm{~km}$ pressure altitude the prognostic model has been used. The rate constants of the gas phase and heterogeneous reactions were taken from Sander et al. (2003). The photolysis rates are calculated online with the Fast-J2 scheme of Bian and Prather (2002). The distributions of chemical species in the KASIMA simulation used here were initialized on 30 March 2002 with results from a long-term KASIMA simulation.

\subsection{ECHAM5/MESSy1}

The atmospheric chemistry general circulation model ECHAM5/MESSy1 Version 1.4 (hereafter denoted as E5M1) is a combination of the general circulation model ECHAM5 (Roeckner et al., 2006) and the Modular Earth Submodel System (MESSy1, Jöckel et al. (2005), http://www.messyinterface.org). Here we analyse data for the year 2003 from the S1 simulation (covering the period 1998 to 2005) described by Jöckel et al. (2006). For this simulation a comprehensive atmospheric chemistry setup for the troposphere, the stratosphere and the lower mesosphere has been applied. The model simulation was performed in T42L90MA resolution, i.e., with a triangular truncation at wave number 42 for the spectral core of ECHAM5, which corresponds to a quadratic Gaussian grid of approximately $2.8^{\circ} \times 2.8^{\circ}$ degrees in latitude and longitude, and with 90 vertical layers from the surface up to $0.01 \mathrm{hPa}$ (approx. $80 \mathrm{~km}$ ). A Newtonian relaxation technique of the prognostic variables temperature, vorticity, divergence and the (logarithm of the) surface pressure above the boundary layer and below $100 \mathrm{hPa}$ towards ECMWF operational analysis data has been applied, in order to nudge the model dynamics towards the observed meteorology. For further details of the model and the model setup of the S1 simulation, we refer to Jöckel et al. (2006).

In addition, we performed an E5M1 sensitivity simulation with the same horizontal, but a lower vertical resolution with 39 layers up to $0.01 \mathrm{hPa}$ (T42L39MA). The chemistry setup was reduced to focus on stratospheric ozone chemistry with a simplified description of the tropospheric ozone chemistry. The MESSy-submodels used for this simulation describe the following processes: ONLEM for "online" emissions of tracers and aerosols, OFFLEM for "offline" emissions of tracers and aerosols, TNUDGE for tracer nudging (Kerkweg et al., 2006a), DRYDEP for dry deposition of trace gases and aerosols, SEDI for the sedimentation of aerosol particles (Kerkweg et al., 2006b), MECCA for the gas-phase chemistry (Sander et al., 2005), JVAL for the calculation of photolysis rates (Landgraf and Crutzen, 1998), SCAV for the scavenging and liquid phase chemistry in cloud and precipitation (Tost et al., 2006a), CONVECT for the parameterization of convection (Tost et al., 2006b), LNOX for the source of NOx produced by lightning (Tost et al., 2007b), PSC for the processes related to polar stratospheric clouds (Buchholz, 2005), QBO for nudging the quasi-biennial oscillation (Giorgetta et al., 2006), PTRAC for additional prognostic tracers (Jöckel et al., 2008), CVTRANS for convective tracer transport, TROPOP for diagnosing the tropopause 
and boundary layer height, $\mathrm{H} 2 \mathrm{O}$ for stratospheric water vapor, RAD4ALL for the radiation calculation, HETCHEM for calculating reaction coefficients of heterogeneous reactions on aerosols (see Jöckel et al. (2006) and references therein) as well as CLOUD for calculating the cloud cover as well as cloud micro-physics including precipitation (Tost et al., 2007a). For this sensitivity simulation, covering the period from the begin of 2000 to the end of 2007, the model dynamics was also nudged (up to $10 \mathrm{hPa}$ ) towards the ECMWF operational analysis. For the analysis presented here, we used data for the year 2003.

\section{Satellite data}

\subsection{Odin/SMR}

The Odin satellite is operated by the Swedish Space Cooperation in cooperation with groups from France, Canada and Finland (Murtagh et al., 2002). Odin was launched on 20 February 2001 and carries two instruments, the Optical Spectrograph and Infrared Imaging System (OSIRIS) (Llewellyn et al., 2004) and the Sub-Millimetre Radiometer (SMR) (Frisk et al., 2003). Observations of thermal emission of trace gases originating from the Earth's limb are performed in a time-sharing mode with astronomical observations. In aeronomy mode, various target bands are dedicated to profile measurements of trace constituents relevant to stratospheric and mesospheric chemistry and dynamics such as $\mathrm{O}_{3}, \mathrm{ClO}, \mathrm{N}_{2} \mathrm{O}, \mathrm{HNO}_{3}, \mathrm{H}_{2} \mathrm{O}, \mathrm{CO}$, and $\mathrm{NO}$, as well as isotopes of $\mathrm{H}_{2} \mathrm{O}$ and $\mathrm{O}_{3}$ (e.g., Murtagh et al., 2002). Aeronomy mode measurements are performed twice a week until April 2007 and every other day thereafter. A typical stratospheric mode scan covers the altitude range from 7 to $70 \mathrm{~km}$ with a resolution of $\approx 1.5 \mathrm{~km}$ in terms of tangent altitude below $50 \mathrm{~km}$ and $\approx 5.5 \mathrm{~km}$ above. Usually, the latitude range between $82.5^{\circ} \mathrm{S}$ and $82.5^{\circ} \mathrm{N}$ is covered by the measurements (Urban et al., 2005a,b).

For the retrieval of vertical profiles from the spectral measurements of a limb scan (aeronomy level-2 processing) two similar data processors have been developed. Here, we use Odin/SMR version 2.1 (Chalmers v2.1) data from the $501.8 \mathrm{GHz}$ band. $\mathrm{N}_{2} \mathrm{O}$ and $\mathrm{O}_{3}$ profiles are retrieved from $\approx 12$ to $60 \mathrm{~km}$ and $\approx 13$ to $65 \mathrm{~km}$, respectively, with an altitude resolution of $1.5 \mathrm{~km}$ and $3 \mathrm{~km}$, respectively. The Odin/SMR $\mathrm{N}_{2} \mathrm{O}$ data are validated in the range $\approx 15$ $50 \mathrm{~km}$. The systematic error is estimated to be $\leq 12 \mathrm{ppbv}$ above $20 \mathrm{~km}$ and in the range of $12-35 \mathrm{ppbv}$ (up to 10 $15 \%$ ) below (Urban et al., 2005a). Extensive validation of Odin/SMR has been conducted, especially with the spaceborne sensors Michelson Interferometer for Passive Atmospheric Soundings (MIPAS/ENVISAT), Atmospheric Chemistry Experiment-Fourier Transform Spectrometer (ACEFTS) and the Aura Microwave Limb Sounder (AuraMLS). Validation of Odin/SMR $\mathrm{N}_{2} \mathrm{O}$ with MIPAS/ENVISAT showed a good overall agreement within 4-7 ppbv (Urban et al., 2005b, 2006). Further, validation studies by Strong et al. (2008) and Lambert et al. (2007) showed a very good agreement of Odin/SMR with ACE-FTS (better than $-20 \%$ ) and with Aura-MLS (better than 4-10\%), respectively. The systematic error of Odin/SMR $\mathrm{O}_{3}$ measurements is estimated to be lower than $0.6 \mathrm{ppmv}$. Odin/SMR measurements of $\mathrm{O}_{3}$ derived with the Chalmers Version 2.1 retrieval algorithm were validated by Jégou et al. (2008) and showed a good agreement of Odin/SMR Version 2.1 data with ground-based $(-0.15 \pm 0.3 \mathrm{ppmv})$, balloon-borne $(-0.7 \pm 1 \mathrm{ppmv})$ and space-borne sensors $(-0.3 \pm 0.2 \mathrm{ppmv})$. The intercomparison of Odin/SMR ozone measurements with MIPAS/ENVISAT and balloon sonde data by Jones et al. (2007) showed an agreement within $10 \%$ between 17 and $55 \mathrm{~km}$ (a maximum deviation of $0.42 \mathrm{ppmv}$ ) and $5-10 \%$ between 25 and $35 \mathrm{~km}$ (less than $0.5 \mathrm{ppmv}$ below $33 \mathrm{~km}$ ). The validation study of ACE-FTS ozone measurements (Dupuy et al., 2009) showed a good agreement between ACE-FTS and Odin/SMR. The agreement between both instruments is better than $+14 \%(0.5 \mathrm{ppmv})$ below $25 \mathrm{~km}$. Between 25 and $40 \mathrm{~km}$ the percentage differences were somewhat larger, ranging between 13-20\%.

\subsection{ILAS/ILAS-II}

The Improved Limb Atmospheric Spectrometers ILAS and ILAS-II used the solar occultation technique which measures the absorption of stratospheric species in the infrared region of solar radiation (Yokota et al., 2002; Oshchepkov et al., 2005). The measurements were made in high latitude regions of the Northern and Southern Hemisphere covering the latitudes from $56^{\circ} \mathrm{N}$ to $70^{\circ} \mathrm{N}$ and from $63^{\circ} \mathrm{S}$ to $88^{\circ} \mathrm{S}$ (ILAS) and between $54^{\circ} \mathrm{N}$ to $71^{\circ} \mathrm{N}$ and $64^{\circ} \mathrm{S}$ and $88^{\circ} \mathrm{S}$ (ILASII). Measurements of vertical profiles of $\mathrm{O}_{3}, \mathrm{HNO}_{3}, \mathrm{NO}_{2}$, $\mathrm{N}_{2} \mathrm{O}, \mathrm{CH}_{4}, \mathrm{H}_{2} \mathrm{O}$, CFC-11, CFC-12, $\mathrm{ClONO}_{2}$, and $\mathrm{N}_{2} \mathrm{O}_{5}$ were made 14 times per day in each hemisphere (Nakajima et al., 2006b,a) with a vertical resolution of $1 \mathrm{~km}$. ILAS was launched onboard the Earth Observing Satellite (ADEOS) on 17 August 1996 and measured continuously from 30 October 1996 to 30 June 1997 (Sasano et al., 1999) while ILASII was launched on 14 December 2002 onboard ADEOS-II and measured continuously from 2 April 2003 to 24 October 2003 (Nakajima et al., 2006b).

Here, we use ILAS Version 6.1 (Nakajima et al., 2006a) and ILAS-II Version 2 data. Validation studies of ILAS Version 5.2 and ILAS-II Version 1.4 ozone data (Sugita et al., 2002; Sugita et al., 2006) show a good agreement with correlative measurements between 11 and $64 \mathrm{~km}$ and between 11 and $40 \mathrm{~km}$, respectively. The validation of ILAS Version 6.1 nitrous oxide data by Kanzawa et al. (2002) shows a good agreement between 10 and $40 \mathrm{~km}$ while ILAS-II Version 1.4 nitrous oxide data tend to be $10 \%$ lower in comparison to the Odin/SMR data and balloon-borne measurements (Ejiri et al., 2006). The latest Version 2 of ILAS-II 
has been improved compared to the former Version 1.4 by an improved transmittance correction in the Northern Hemisphere, by using HITRAN 2004 (Rothman et al., 2005) parameters instead of HITRAN 2000 (Rothman et al., 2003) parameters and by an improved tangent height registration (Tanaka et al., 2007). The intercomparison studies of Version 1.4 and Version 2 target species by Griesfeller et al. (2008) and Wetzel et al. (2008) show an improvement of the $\mathrm{O}_{3}$ data in the Northern Hemisphere compared to the former Version 1.4 and a good agreement with measurements from MIPAS/ENVISAT and the balloon-borne MIPAS-B, respectively, between 16 and $31 \mathrm{~km}$. The differences between ILAS-II Version 2 and MIPAS/ENVISAT were about 0.3 ppmv (8-10\%) while between ILAS-II and MIPAS-B mean differences of about $-10.0 \%$ (Version 2) and $-6.3 \%$ (Version 1.4) respectively, were found. Differences between the two retrieval versions were small for $\mathrm{N}_{2} \mathrm{O}$ and a good agreement with MIPAS/ENVISAT and MIPAS-B measurements was found as well between 16 and $31 \mathrm{~km}$. The largest differences between ILAS-II and MIPAS/ENVISAT $\mathrm{N}_{2} \mathrm{O}$ were found at $13 \mathrm{~km}$ and $14 \mathrm{~km}$ with values of $0.04 \mathrm{ppmv}$ $(10 \%)$ and $0.05 \mathrm{ppmv}(15 \%)$ for ILAS-II Version 2 and Version 1.4, respectively. Mean differences between MIPAS-B and ILAS-II were about $-11 \%$ for both versions.

To derive a one year data set for the Northern and Southern Hemisphere high latitude region the measurements of ILAS and ILAS-II were combined (Khosrawi et al., 2006). Thus, the months from January to June and November and December are covered by ILAS and the months from July to October by ILAS-II. The comparison of ILAS with ILAS-II for the months where both instruments measured showed a good agreement between both data sets and demonstrated that differences between the different years considered are low in the monthly averages of $\mathrm{N}_{2} \mathrm{O}$ and $\mathrm{O}_{3}$ (Khosrawi et al., 2006).

\section{The $\mathrm{O}_{3} / \mathrm{N}_{2} \mathrm{O}$ distribution in the polar lower strato- sphere}

Proffitt et al. (2003) have suggested a somewhat different way to use stratospheric tracer-tracer correlations than in the commonly employed method to deduce chemical polar ozone loss (e.g., Proffitt et al., 1993; Tilmes et al., 2003; Müller et al., 2005). Proffitt et al. (2003) calculated monthly averages of $\mathrm{N}_{2} \mathrm{O}$ and $\mathrm{O}_{3}$ by binning the data by altitude or potential temperature and then averaging over a fixed interval of $\mathrm{N}_{2} \mathrm{O}(20 \mathrm{ppbv})$. This method helps to separate $\mathrm{O}_{3}$ variability due to latitudinal transport from photochemical changes. Thus, the changes in the families of curves derived by using the method of Proffitt et al. (2003) are not only caused by chemical ozone loss or production, but also by transport processes (Proffitt et al., 2003; Khosrawi et al., 2004, 2006; Khosrawi et al., 2008). Note that in contrast to the classical $\mathrm{O}_{3}$-tracer correlation method compactness of the $\mathrm{O}_{3}$ tracer relationship is not required for this method. For test- ing model performance we require that the monthly averages of $\mathrm{O}_{3}$ and $\mathrm{N}_{2} \mathrm{O}$ derived from observations are reproduced by the monthly averages of $\mathrm{O}_{3}$ and $\mathrm{N}_{2} \mathrm{O}$ derived from the model simulations within the variability of the observations. How diabatic descent influences the families of curves has been shown in detail by Khosrawi et al. (2008) using the relationship between $\mathrm{N}_{2} \mathrm{O}$ and potential temperature. Here, we will only discuss how the families of curves are influenced by diabatic descent as well as by winter and summer ozone destruction in the Northern Hemisphere polar regions on the basis of a schematic figure (Fig. $1 \mathrm{a}-\mathrm{c}$ ). The curves used in this schematic figure (Fig. 1 a-c, but not $1 \mathrm{~d}$ ) were taken on certain altitude levels from the 1-year data set of monthly averages of $\mathrm{N}_{2} \mathrm{O}$ and $\mathrm{O}_{3}$ derived from ILAS/ILAS-II observations (Khosrawi et al., 2006).

The general characteristic of the families of curves derived from monthly averages of $\mathrm{N}_{2} \mathrm{O}$ and $\mathrm{O}_{3}$ binned by altitude or potential temperature is a positive correlation (increasing $\mathrm{N}_{2} \mathrm{O}$ with increasing $\mathrm{O}_{3}$ ) at the upper levels (above $500 \pm 25 \mathrm{~K}$ or $20 \mathrm{~km}$ ) and a negative correlation (decreasing $\mathrm{N}_{2} \mathrm{O}$ with increasing $\mathrm{O}_{3}$ ) at the lower levels (below $500 \pm 25 \mathrm{~K}$ ). The positive correlation at the levels above $500 \pm 25 \mathrm{~K}$ is caused by diabatic descent of air from above the $\mathrm{O}_{3}$ maximum (Proffitt et al., 2003). Strong descent results in a steepening of the positively correlated curves and thus, the stronger the descent the stronger the steepening (Khosrawi et al., 2004). How descent affects the curves in the polar regions is schematically shown on one curve $(25 \mathrm{~km}, \approx 550 \mathrm{~K})$ in Fig. 1 (bottom:left) for the Northern Hemisphere for June and November. In June when descent is weak a negative correlation is found while in November when descent increases in strength the correlation changes to positive (increasing $\mathrm{N}_{2} \mathrm{O}$ with increasing $\mathrm{O}_{3}$ ). At and below $500 \pm 25 \mathrm{~K}$ the curves are influenced by a combination of diabatic descent and polar winter ozone loss. Descent is visible in these curves as an extension of the curves to $\mathrm{N}_{2} \mathrm{O}$ mixing ratios $<50 \mathrm{ppbv}$ and ozone loss by a change of slope. Substantial subsidence is generally observed in the Northern and Southern Hemisphere polar regions from fall to spring (e.g., Proffitt et al., 1989b; Tuck, 1989; Russell et al., 1993; Rosenfield et al., 1994). However, as discussed by Khosrawi et al. (2008) diabatic descent is in the monthly averages to a certain extent masked by tropical ozone production when the entire hemisphere is considered. Thus, the separation in photochemical and dynamical processes can be most easily performed when only the polar regions are considered.

Polar winter ozone loss causes an inflection of the curves (below $550 \mathrm{~K}$ ) and therefore a change of slope (Fig. 1, top:left). Thus, the slope of the curves change from negative (at high $\mathrm{N}_{2} \mathrm{O}$ mixing ratios) to positive correlated (at low $\mathrm{N}_{2} \mathrm{O}$ mixing ratios). In general, when the maximum ozone loss is reached, this change of slope develops into a minimum in $\mathrm{O}_{3}$ at around $50 \mathrm{ppbv} \mathrm{N}_{2} \mathrm{O}$ (especially in the Southern Hemisphere). Figure 1 (top:left) shows this schematically for the curve at $20 \pm 2.5 \mathrm{~km}$ altitude $(\approx 500 \pm 25 \mathrm{~K})$ comparing 

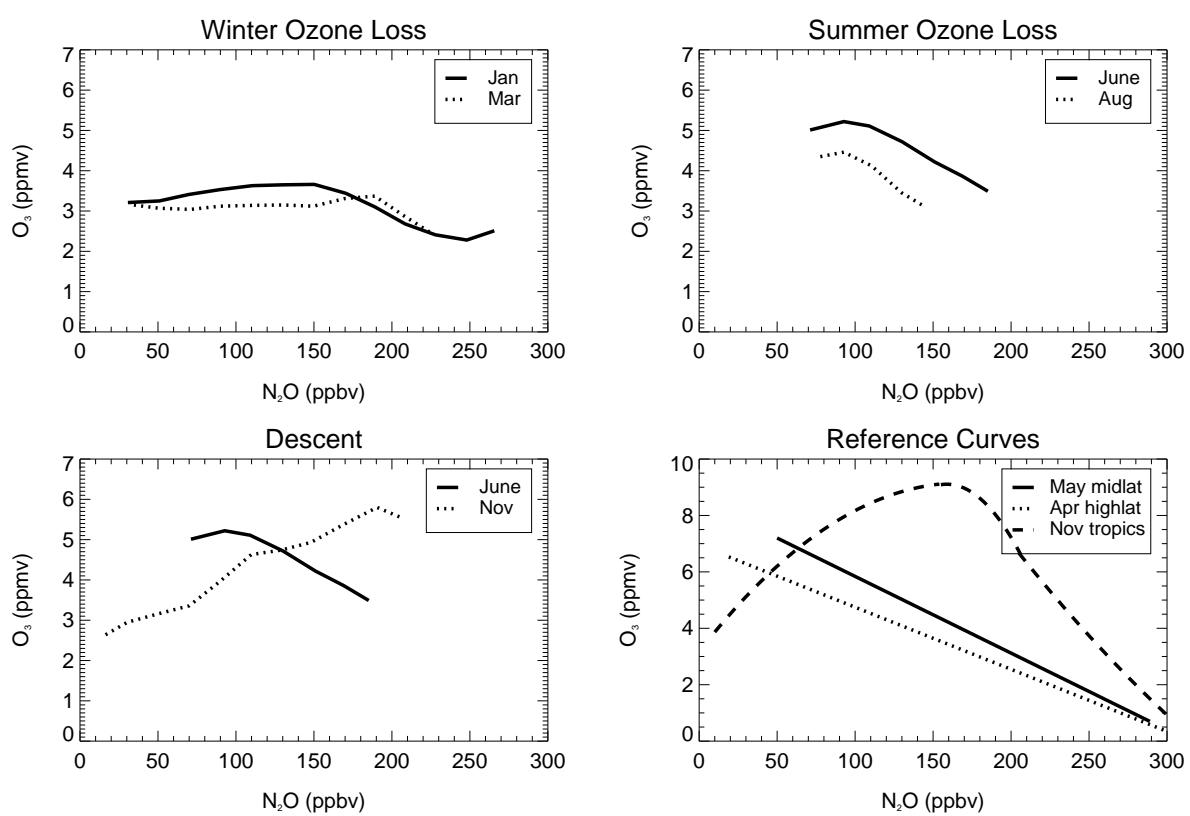

Fig. 1. Schematic of the change of the $\mathrm{N}_{2} \mathrm{O}$ and $\mathrm{O}_{3}$ distribution in the Northern Hemisphere polar region due to photochemical winter ozone loss at a selected altitude level of $20 \pm 2.5 \mathrm{~km}$ which agrees with $\approx 450 \mathrm{~K}$ (top:left) and photochemical summer ozone loss at a selected altitude level of $25 \pm 2.5 \mathrm{~km}$ which agrees with $\approx 550 \mathrm{~K}$ (top:right) and diabatic descent at a selected altitude level of $25 \pm 2.5 \mathrm{~km}$ which agrees with $\approx 550 \mathrm{~K}$ (bottom:left) based on ILAS/ILAS-II data as well as reference curves (bottom:right) for the midlatitudes (May, ATMOS Shuttle 1985, solid line), highlatitudes (April, ATMOS Shuttle 1993, dotted line) and tropics (November, ATMOS Shuttle 1994, dashed curve) based on ATMOS shuttle measurements. These reference curves were derived from measurements made in the altitude region from $12-80 \mathrm{~km}$. Note, while the curves in Fig. a-c are for a certain altitude level, the reference curves in Fig. $d$ are derived from all measurements made at a certain latitude region. See text for further details.

the months January and March for the Northern Hemisphere. In January a change of slope is already visible at $150 \mathrm{ppmv}$ $\mathrm{N}_{2} \mathrm{O}$. In March this inflection has shifted to somewhat higher $\mathrm{N}_{2} \mathrm{O}$ mixing ratio (200 pbbv) and $\mathrm{O}_{3}$ mixing ratios have decreased for low $\mathrm{N}_{2} \mathrm{O}$ mixing ratios due to photochemical ozone destruction (Fig. 1, top:left). Evidence for chlorinecatalyzed photochemical $\mathrm{O}_{3}$ destruction during late winter and early spring was reported for both hemispheres for several winters in previous studies based on model results and observations (e.g., Müller et al., 1997; Manney et al., 2003; Tilmes et al., 2004; Goutail et al., 2005; Grooß et al., 2005; WMO, 2007).

The polar summer ozone destruction tends to reduce ozone mixing ratios and thus the magnitude of the negative $\mathrm{O}_{3} / \mathrm{N}_{2} \mathrm{O}$ slope above $25 \pm 2.5 \mathrm{~km}(\approx 550 \pm 25 \mathrm{~K})$ as shown schematically in Figure 1 (top:right) for the curves at $25 \pm 2.5 \mathrm{~km}$ (June and August). In August $\mathrm{O}_{3}$ mixing ratios are lower for all corresponding $\mathrm{N}_{2} \mathrm{O}$ mixing ratios than in June due to photochemical $\mathrm{O}_{3}$ destruction. Summer ozone destruction caused by $\mathrm{NO}_{\mathrm{x}}$ catalysis is found in the Northern Hemisphere from May to August between $\approx 10$ and $100 \mathrm{hPa}$ in the high latitudes and midlatitudes (e.g., Farman et al., 1985; Brühl and Crutzen, 2000). A detailed description of the method and characteristics of the $\mathrm{N}_{2} \mathrm{O} / \mathrm{O}_{3}$ distribution can be found in Khosrawi et al. (2008) and references therein.
Reference curves for the tropical, midlatitudes, and polar regions (but not for potential temperature regimes) have been derived from measured correlations of $\mathrm{N}_{2} \mathrm{O}$ and $\mathrm{O}_{3}$ since decades (e.g. Proffitt et al., 1989b; Müller et al., 1996; Michelsen et al., 1998b; Müller et al., 2001). These reference curves were derived from measurements made on different measurement platforms (aircraft, balloon, satellite and space shuttle) and have proven to be consistent with one another when compared seasonally and spatially, and to have distinct relations in the tropics, midlatitudes and polar regions (e.g. Michelsen et al., 1998b; Plumb, 2007). The reference curves for May midlatitudes (ATMOS Shuttle 1985), April high latitudes (ATMOS Shuttle 1993) and November tropics (ATMOS Shuttle 1994) are shown in Fig. 1 (bottom:right). These reference curves were derived from the ATMOS shuttle missions which were performed each with a duration of approximately two weeks. ATMOS is a space-shuttle based high resolution spectrometer, which simultaneously measures the vertical profiles of $\approx 30$ species in the solar occultation mode. ATMOS measurements are performed in the altitude range from $12-80 \mathrm{~km}$ with a vertical resolution of $2-3 \mathrm{~km}$. ATMOS measurements are characterized by high precision, accuracy, and internal consistency (Michelsen et al., 1998a). These reference curves can be used to discriminate between air of tropical character, air of midlatitude character and air of polar 
character (Proffitt et al., 2003). In general, the tropical air has higher $\mathrm{N}_{2} \mathrm{O}$ mixing ratios than the reference curve for the midlatitudes and the tropics while the midlatitude air is centered around the midlatitude reference curve and the high latitude air has $\mathrm{N}_{2} \mathrm{O}$ mixing ratios that are lower than the high latitude and midlatitude reference curves (Proffitt et al., 2003). The reference curves shown in Fig. 1 (bottom:right) were used by Khosrawi et al. (2008) to distinguish between air of polar character and air of tropical character measured by Odin/SMR.

Hegglin and Shepherd (2007) have demonstrated that sampling issues become important when considering hemispheric $\mathrm{O}_{3} / \mathrm{N}_{2} \mathrm{O}$ scatterplots of ACE-FTS measurements that show a much higher sampling of the extratropics than of the tropics (Fig. 6 in their paper). The reference relations shown in Figure 1d emphasizes the fact that different tracer relations develop in the tropics, midlatitudes and polar regions (e.g. Proffitt et al., 1993; Müller et al., 1996; Michelsen et al., 1998b; Proffitt et al., 2003; Plumb, 2007). This observation is consistent with the $\mathrm{N}_{2} \mathrm{O} / \mathrm{O}_{3}$ PDFs derived from the ACEFTS data in so far as the reference relations shown in Fig. 1 agree with the enhancements in the ACE-FTS $\mathrm{N}_{2} \mathrm{O} / \mathrm{O}_{3}$ PDFs for the appropriate season and latitude region (black contour lines in Figure 8 in Hegglin and Shepherd (2007)).

In Fig. 2 monthly averages of $\mathrm{N}_{2} \mathrm{O}$ and $\mathrm{O}_{3}$ derived from Odin/SMR at $500 \pm 25 \mathrm{~K}$ and $650 \pm 25 \mathrm{~K}$ for the year 2003 are compared with the two following years (2004 and 2005). As can be seen from this figure, differences between monthly averaged $\mathrm{N}_{2} \mathrm{O}$ and $\mathrm{O}_{3}$ binned by potential temperature are low between different years and can clearly be distinguished from model deficiencies.

\section{Model evaluation}

Here, we evaluate simulations of stratospheric ozone by the models CLaMS, KASIMA and E5M1. For this purpose, monthly averages of $\mathrm{N}_{2} \mathrm{O}$ and $\mathrm{O}_{3}$ were calculated from the model results. For the evaluation of CLaMS, KASIMA and E5M1 the $500 \pm 25 \mathrm{~K}$ and $650 \pm 25 \mathrm{~K}$ potential temperature level were chosen. These levels were chosen since at $500 \pm 25 \mathrm{~K}$ polar winter ozone loss is pronounced and at $650 \pm 25 \mathrm{~K}$ descent is pronounced. However, it should be noted here that the $500 \pm 25 \mathrm{~K}$ curve is influenced by both descent and ozone loss but with ozone loss being the dominant process (Sect. 4). The Odin/SMR data were taken as the basis for the model evaluation since from Odin/SMR global measurements are available. This allows us evaluating the models not only for the entire hemisphere (considering all latitudes between $0^{\circ}-90^{\circ}$ ), but also separated into the latitude regimes high latitudes $\left(60^{\circ}-90^{\circ}\right)$, midlatitudes $\left(30^{\circ}-60^{\circ}\right)$ and low latitudes $\left(0^{\circ}-30^{\circ}\right)$. Further, to investigate the differences caused by using different data sets as reference, we will evaluate CLaMS, KASIMA and E5M1 for the polar regions using ILAS/ILAS-II as reference

\section{Polar Regions $(\mathrm{NH})$}
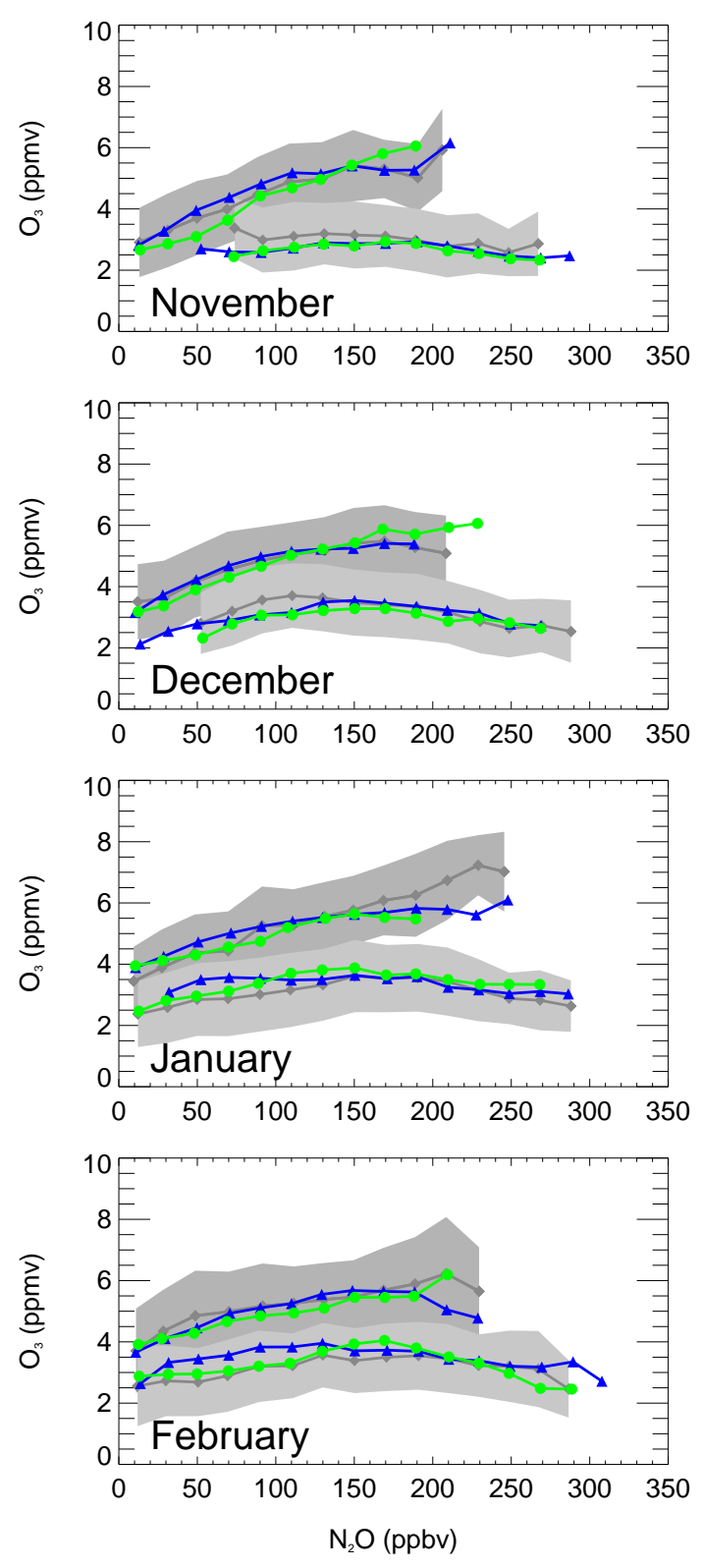

$$
\begin{aligned}
& \longleftrightarrow \text { Odin } 2003(500 \mathrm{~K}) \\
& \longleftrightarrow \text { Odin } 2004(500 \mathrm{~K}) \\
& \longleftrightarrow \text { Odin } 2005(500 \mathrm{~K}) \\
& \longleftrightarrow \text { Odin } 2003(650 \mathrm{~K}) \\
& \longleftrightarrow \text { Odin } 2004(650 \mathrm{~K}) \\
& \longrightarrow \text { Odin } 2005(650 \mathrm{~K})
\end{aligned}
$$

Fig. 2. Comparison of monthly averages of $\mathrm{N}_{2} \mathrm{O}$ and $\mathrm{O}_{3}$ derived from Odin/SMR for the years 2004 (blue triangles) and 2005 (green circles) with monthly averages of $\mathrm{N}_{2} \mathrm{O}$ and $\mathrm{O}_{3}$ derived from Odin/SMR for the year 2003 (grey diamonds) at $500 \pm 25 \mathrm{~K}$ and $650 \pm 25 \mathrm{~K}$ (Northern Hemisphere polar regions). The grey shaded area marks the range of the standard deviations of the monthly averages of $\mathrm{O}_{3}$ derived from Odin/SMR data for the year 2003. Here and in the following figures the $\mathrm{N}_{2} \mathrm{O}$ data is binned by 20 ppbv $\mathrm{N}_{2} \mathrm{O}$. 
(Sect. 5.3). Moreover, we assess the effect of using a coarser spatial resolution in the model simulation by comparing the E5M1 T42L90 simulation with a T42L39 simulation. The differences $D$ between Odin/SMR, ILAS/ILASII, CLaMS, KASIMA and E5M1 are calculated as follows: $D=[\mu($ Model $)-\mu($ Odin $)] / \mu($ Odin $) * 100$, where $\mu$ denotes the $\mathrm{O}_{3}$ mixing ratio at a given $\mathrm{N}_{2} \mathrm{O}$ mixing ratio of the Odin/SMR measurement and the model simulation, respectively. The agreement is considered to be satisfactory between the Odin/SMR measurements and model simulations in case of differences within $\pm 20 \%$ (which roughly agrees with $1 \sigma$ of the Odin/SMR measurements) and to be reasonable for differences within $\pm 40 \%$.

The evaluation was performed for the Northern Hemisphere for the months November to February. These months have been chosen since the CLaMS simulation covers only the months from November to March. However, these months are particularly suitable to test the performance of the models during the Arctic winter, that is, during a period of significant chemical $\mathrm{O}_{3}$ loss. To give an overview over the performance of the models for each month of the year, we calculated the averages of the differences for each month (which will be discussed in Sect. 5.5).

The strategy of this evaluation was to not consider a certain winter, but to perform a general evaluation. The data of the models and the measurements were primarily taken for the year 2003. However, since the CLaMS simulation was performed for the winter 2002/2003, the months November and December are for 2002. Further, since the months considered here were measured by ILAS (and not by ILAS-II) this data is for the years 1996 (November and December) and 1997 (January and February). However, the principal dynamical and chemical processes in each winter are the same and only the strength of these processes changes from year to year, thus small differences can occur in the monthly averaged $\mathrm{N}_{2} \mathrm{O} / \mathrm{O}_{3}$ distributions from the usage of different years but these differences are clearly distinguishable from model deficiencies (Khosrawi et al., 2006; Khosrawi et al., 2008). How small the differences between different years are can be seen from Figure 2 where the monthly averages of $\mathrm{N}_{2} \mathrm{O}$ and $\mathrm{O}_{3}$ derived from Odin/SMR at $500 \pm 25 \mathrm{~K}$ and $650 \pm 25 \mathrm{~K}$ are shown for three different years.

The evaluation of CLaMS, KASIMA and E5M1 is shown in figure 4 for the entire Northern Hemisphere, and, separated into latitude regimes, in Figures 5-7. The range of standard deviation of the monthly averaged $\mathrm{O}_{3}$ derived from Odin/SMR are marked as a grey shaded area while standard deviations of the models are not included to keep the figures more concise. Standard deviations of the models are generally $<5$ ppbv for $\mathrm{N}_{2} \mathrm{O}$ and $<0.5$ ppmv for $\mathrm{O}_{3}$. Figure 3 shows the comparison of the models with Odin/SMR including the standard deviations for one month (March, Northern Hemisphere) to give a better impression on the magnitude of the standard deviations of the models.

\section{$5.1 \quad$ All latitude regimes $(\mathrm{NH})$}

In Fig. 4, the evaluation for the Northern Hemisphere for the months November to February is shown. As described in Sect. 4, a positive to flat correlation is found at $650 \pm 25 \mathrm{~K}$ and a negative correlation at $500 \pm 25 \mathrm{~K}$. In November CLaMS, KASIMA and E5M1 agree quite well with Odin/SMR. In the monthly averages, solely at $\mathrm{N}_{2} \mathrm{O}$ mixing ratios larger than $230 \mathrm{ppbv}$ lower $\mathrm{O}_{3}$ mixing ratios are derived from the model simulations than derived from Odin/SMR observations. Here, the differences in the averaged $\mathrm{O}_{3}$ mixing ratios increase up to $-40 \%$. While the KASIMA and E5M1 curves for $500 \pm 25 \mathrm{~K}$ do not extend to $\mathrm{N}_{2} \mathrm{O}$ mixing ratio as low as derived from Odin/SMR (70 ppbv $\left.\mathrm{N}_{2} \mathrm{O}\right)$ lower $\mathrm{N}_{2} \mathrm{O}$ mixing ratios are found in the CLaMS simulation (30 ppbv $\mathrm{N}_{2} \mathrm{O}$ ). This indicates that in CLaMS a stronger descent is simulated than observed in November while in KASIMA and E5M1 the descent is simulated slightly less than observed at that time. At $650 \pm 25 \mathrm{~K}$ CLaMS and E5M1 agree quite well with Odin/SMR with differences in the averaged $\mathrm{O}_{3}$ mixing ratios within $+10 \%$ and $+20 \%$, respectively. Somewhat larger differences (generally in the range of $\pm 20 \%$ ) are found for KASIMA, especially at $\mathrm{N}_{2} \mathrm{O}$ mixing ratios lower than $100 \mathrm{ppbv}$ and larger than $250 \mathrm{ppbv}$. Similar results are found for December, but in all models at $500 \pm 25 \mathrm{~K}$ as well as at $650 \pm 25 \mathrm{~K}$ larger deviations from Odin/SMR are found at $\mathrm{N}_{2} \mathrm{O}$ greater $250 \mathrm{ppbv}$ which can be attributed to influence of air of tropical character (air with higher $\mathrm{N}_{2} \mathrm{O}$ mixing ratios than the tropical reference curve, see Fig. 1 (bottom:right)), thus, indicating differences of the model simulation in the tropical regions (Fig. 4, December). These differences will be discussed in more detail in section 5.2.1. However, the ozone differences for the averaged $\mathrm{N}_{2} \mathrm{O}$ mixing ratios range generally within $\pm 20 \%$ for all models.

From January on, ozone loss is visible at $500 \pm 25 \mathrm{~K}$ by an inflection and a change of slope from positively to negatively correlated. In the Odin/SMR monthly averages as well as in CLaMS and KASIMA monthly averages this inflection is found at $190 \mathrm{ppbv}$ while in E5M1 this inflection is shifted slightly and is found at $210 \mathrm{ppbv}$ (Fig. 4, left, January). This shift in the inflection is caused by an underdetermination of ozone destruction during polar winter in E5M1. Further, while in CLaMS, KASIMA and Odin/SMR the $\mathrm{O}_{3}$ mixing ratios tend to decrease with decreasing $\mathrm{N}_{2} \mathrm{O}$ this is not found in E5M1. Here, the mixing ratios tend rather to increase confirming too that polar ozone loss in the model is underestimated. This will be discussed in more detail in Sect. 5.2.3.

In general, the monthly averages of $\mathrm{N}_{2} \mathrm{O}$ and $\mathrm{O}_{3}$ derived from CLaMS, KASIMA and E5M1 simulations are in agreement with Odin/SMR measurements with differences in $\mathrm{O}_{3}$ mixing ratios in the range of $\pm 20 \%$ if the entire Northern Hemisphere (all latitudes) is considered. Differences at $500 \pm 25 \mathrm{~K}$ are somewhat larger than at $650 \pm 25 \mathrm{~K}$, especially at $\mathrm{N}_{2} \mathrm{O}$ mixing ratios greater than $200 \mathrm{ppbv}(500 \pm 25 \mathrm{~K})$ and 


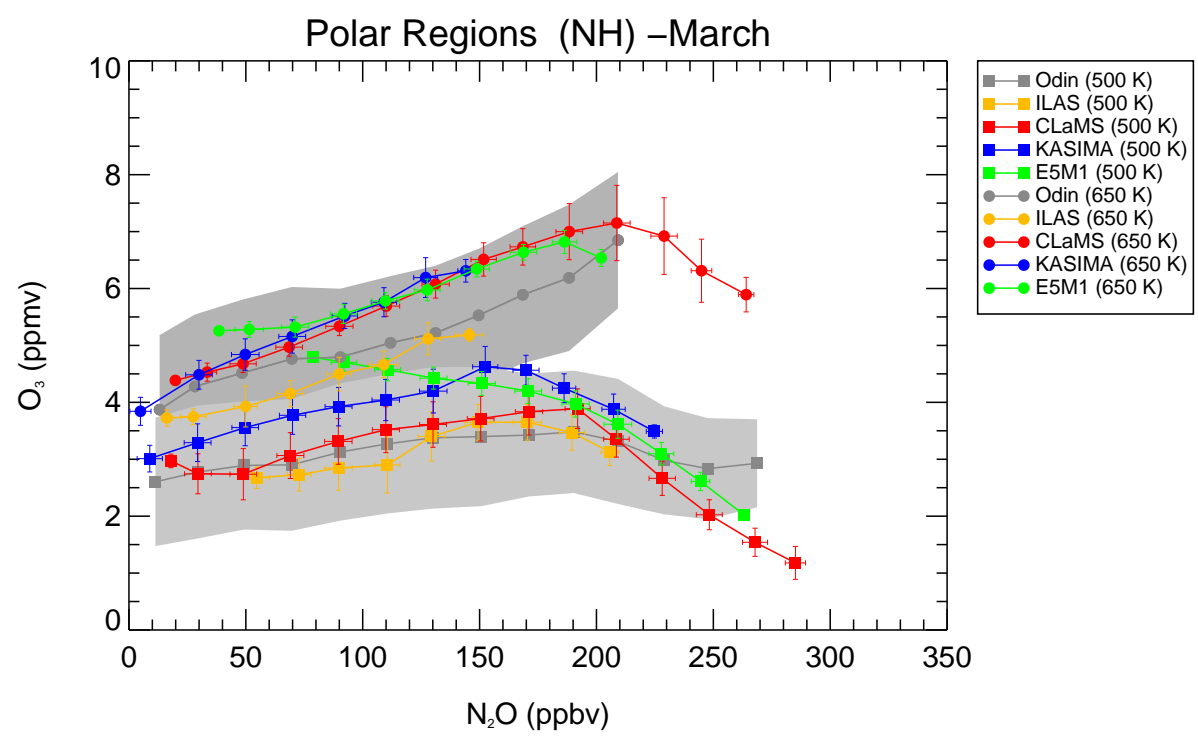

Fig. 3. Monthly averages of $\mathrm{N}_{2} \mathrm{O}$ and $\mathrm{O}_{3}$ derived from CLaMS, KASIMA, E5M1, ILAS/ILAS-II (colored curves) and Odin/SMR (grey) at $500 \pm 25 \mathrm{~K}$ (squares) and $650 \pm 25 \mathrm{~K}$ (circles) for the Northern Hemisphere (March). The grey shaded area marks the range of the standard deviations of the monthly averages of $\mathrm{O}_{3}$ derived from Odin/SMR. Standard deviations of the models and ILAS/ILAS-II are given as error bars.

$250 \mathrm{ppbv}(650 \pm 25 \mathrm{~K})$, respectively, larger differences are found. In all models, differences increase here up to $-40 \%$.

\subsection{Separation into latitude regimes (NH)}

In the following the evaluation will be performed separately for three latitude regions: high latitudes $\left(60^{\circ}\right.$ to $\left.90^{\circ} \mathrm{N}\right)$, midlatitudes $\left(30^{\circ}\right.$ to $\left.60^{\circ} \mathrm{N}\right)$ and low latitudes $\left(0^{\circ}\right.$ to $\left.30^{\circ} \mathrm{N}\right)$. The tropics are not truly isolated from the midlatitudes and these are not truly isolated from the high latitudes (e.g. Tuck et al., 1989; Proffitt et al., 1989b; Tuck and Proffitt, 1997; Randel et al., 1993; Michelsen et al., 1998b; Proffitt et al., 2003). Data taken well outside the tropics can be of tropical character (Randel et al., 1993). However, the separation of the $\mathrm{N}_{2} \mathrm{O} / \mathrm{O}_{3}$ data set into the different latitude regimes reveals the rather different characteristics of these air masses (Khosrawi et al., 2008). Generally, in the $\mathrm{N}_{2} \mathrm{O} / \mathrm{O}_{3}$ distribution the region with low $\mathrm{N}_{2} \mathrm{O}$ and high $\mathrm{O}_{3}$ mixing ratios can be attributed to air of polar character and the region with high $\mathrm{N}_{2} \mathrm{O}$ and low $\mathrm{O}_{3}$ mixing ratios can be attributed to air of tropical character while the intermediate region of $\mathrm{N}_{2} \mathrm{O}$ and $\mathrm{O}_{3}$ mixing ratios characterize midlatitude air (Sect. 4 and Fig. 1 (bottom:right)).

\subsubsection{Tropics}

The CLaMS simulation investigated here was focusing on ozone loss in the polar regions and thus was performed with a much lower spatial resolution between 0 and $40^{\circ} \mathrm{N}$ acting mainly as a boundary for the high and midlatitudes. There- fore, the CLaMS data set is not considered in the evaluation of the tropics. In the tropics, changes of the $\mathrm{N}_{2} \mathrm{O} / \mathrm{O}_{3}$ distribution from season to season and between the hemispheres are small (Khosrawi et al., 2008). A flat to positive correlation is generally found above $700 \pm 25 \mathrm{~K}$. The positive correlation is caused by the photochemical production of ozone in the tropics. At potential temperature levels below $550 \pm 25 \mathrm{~K}$ the correlation is influenced by midlatitude air (Khosrawi et al., 2008). For the tropics, a satisfactory agreement is found for KASIMA and E5M1 at $650 \pm 25 \mathrm{~K}$ while a reasonable agreement is found for $500 \pm 25 \mathrm{~K}$. At $500 \pm 25 \mathrm{~K}$ in both models a steeper negative correlation is found which leads to higher $\mathrm{O}_{3}$ mixing ratios at $\mathrm{N}_{2} \mathrm{O}$ mixing ratios smaller than $250 \mathrm{ppbv}$ and lower $\mathrm{O}_{3}$ mixing ratios at $\mathrm{N}_{2} \mathrm{O}$ mixing ratios larger than $250 \mathrm{ppbv}$ (Fig. 5, left, all months). Therefore, differences in averaged $\mathrm{O}_{3}$ mixing ratios change from $+40 \%$ to $-40 \%$ with increasing $\mathrm{N}_{2} \mathrm{O}$. At $650 \pm 25 \mathrm{~K}$ differences are not exceeding $\pm 20 \%$ and averaged $\mathrm{O}_{3}$ derived from KASIMA and E5M1 are generally higher than the ones derived from Odin/SMR (Fig. 5, right, all months). Differences between Odin/SMR and the models are particularly pronounced at $500 \pm 25 \mathrm{~K}$. Indeed, the strong vertical ozone gradients in the tropical lower stratosphere are difficult to resolve with the relatively coarse altitude resolution of Odin/SMR $(3 \mathrm{~km})$. However, transport processes in the tropical lower stratosphere are difficult to represent in models (e.g. Hegglin and Shepherd, 2007), so that the model vs Odin/SMR differences could also be partly due to model deficiencies. To understand this difference in detail further data sets have to be taken into account. However, this is beyond the scope of this study. The same applies 


\section{All Latitudes $(\mathrm{NH})$}
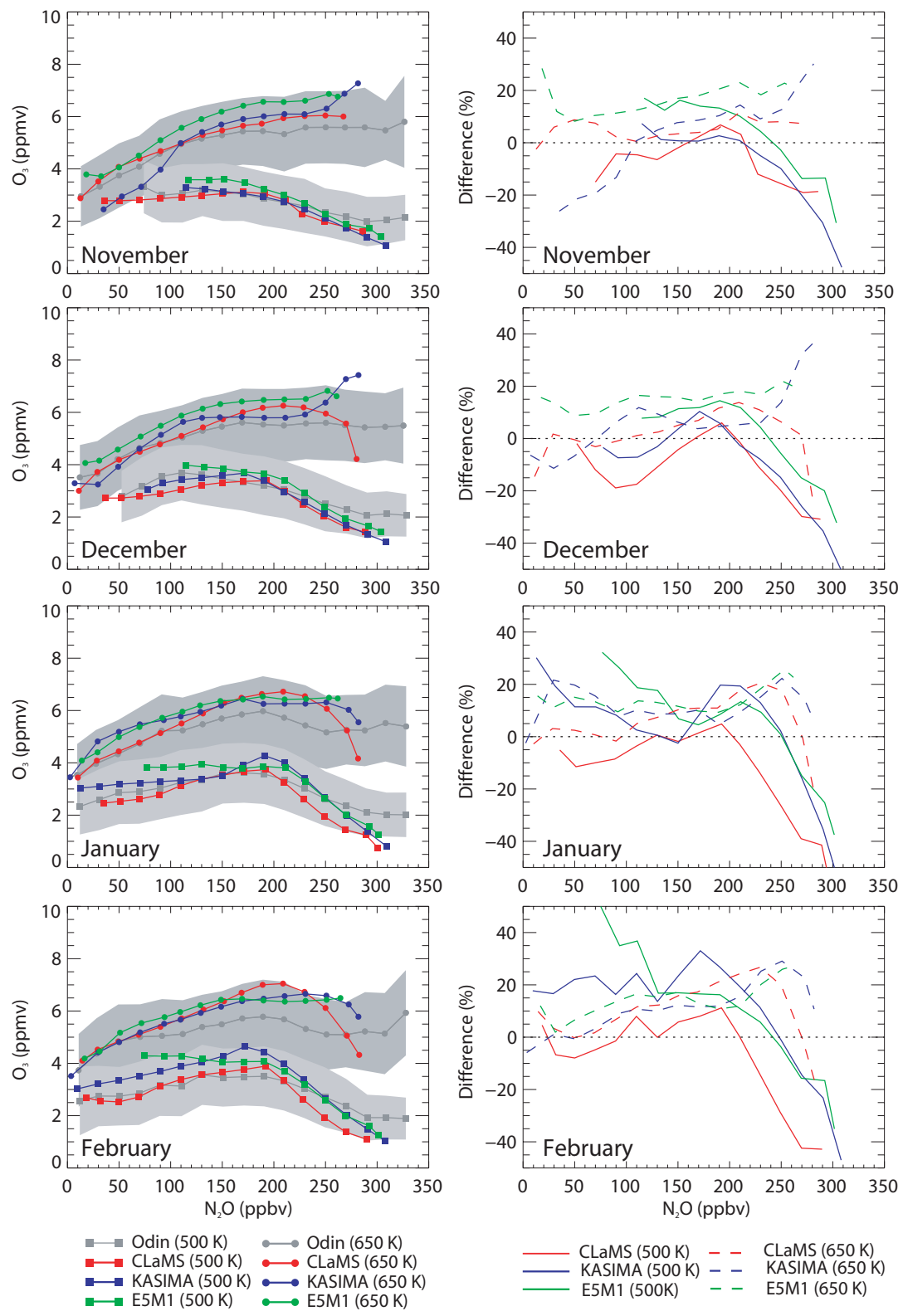

Fig. 4. Northern Hemisphere, all latitudes. Left: Comparison of monthly averages of $\mathrm{N}_{2} \mathrm{O}$ and $\mathrm{O}_{3}$ derived from CLaMS, KASIMA and E5M1 (colored curves) with Odin/SMR (grey) at $500 \pm 25 \mathrm{~K}$ (squares) and $650 \pm 25 \mathrm{~K}$ (circles). The grey shaded area marks the range of the standard deviations of the monthly averages of $\mathrm{O}_{3}$ derived from Odin/SMR. Right: Differences in percentage of the $\mathrm{O}_{3}$ averages of CLaMS, KASIMA and E5M1 from Odin/SMR at 500 $\pm 25 \mathrm{~K}$ (solid curves) and $650 \pm 25 \mathrm{~K}$ (dashed curves). A positive difference means an overestimation of ozone while a negative difference means an underestimation of ozone.

to the unusually high $\mathrm{N}_{2} \mathrm{O}$ values found in the Odin/SMR monthly averages at $650 \pm 25 \mathrm{~K}\left(\mathrm{~N}_{2} \mathrm{O}>300 \mathrm{ppbv}\right)$. It has to be noted that the reported statistical uncertainty of single Odin/SMR data points on that level is of the order of the chosen $\mathrm{N}_{2} \mathrm{O}$ bins size $(1 \sigma \approx 25 \mathrm{ppbv})$. This may lead to an artificial extension of the correlation curves at their ends. This argument is supported by the fact that a rather low number of data points is present in the bins for $\mathrm{N}_{2} \mathrm{O}>300 \mathrm{ppbv}$ compared to other bins. Therefore, we do not further discuss here the monthly averages of $\mathrm{O}_{3}$ and $\mathrm{N}_{2} \mathrm{O}$ derived from Odin/SMR and the differences to the simulations for these bins. 


\section{Tropics $(\mathrm{NH})$}
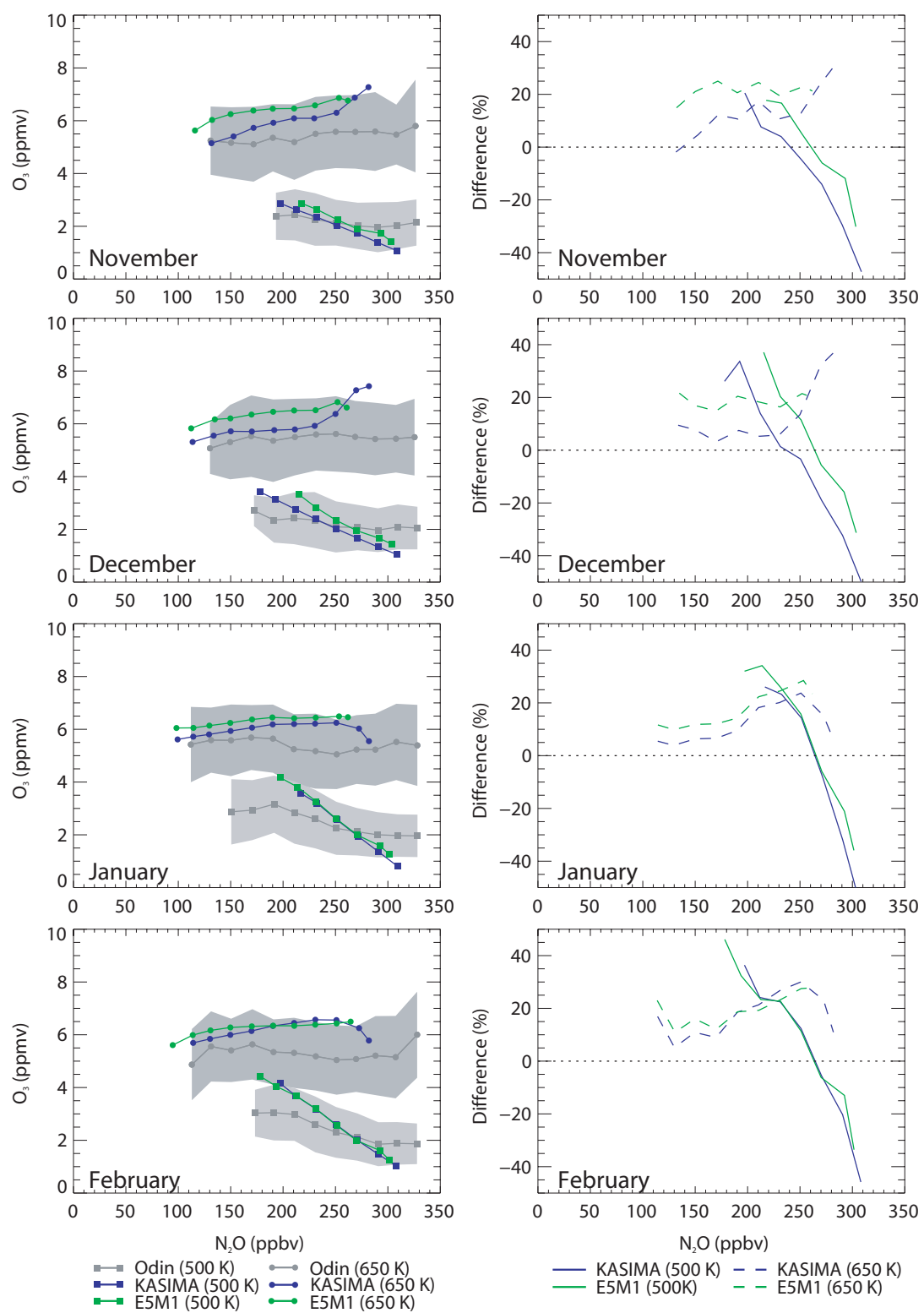

Fig. 5. Northern Hemisphere, tropics. Left: Comparison of monthly averages of $\mathrm{N}_{2} \mathrm{O}$ and $\mathrm{O}_{3}$ derived from KASIMA and E5M1 (colored curves) with Odin/SMR (grey) at $500 \pm 25 \mathrm{~K}$ (squares) and $650 \pm 25 \mathrm{~K}$ (circles). The grey shaded area marks the range of the standard deviations of the monthly averages of $\mathrm{O}_{3}$ derived from Odin/SMR. Right: Differences in percentage of the $\mathrm{O}_{3}$ averages of KASIMA and E5M1 from Odin/SMR at $500 \pm 25 \mathrm{~K}$ (solid curves) and $650 \pm 25 \mathrm{~K}$ (dashed curves). A positive difference means an overestimation of ozone while a negative difference means an underestimation of ozone.

\subsubsection{Midlatitudes}

In the midlatitudes generally an agreement between CLaMS, KASIMA and E5M1 with Odin/SMR observations is found (Fig. 6). In November and December the differences at $650 \pm 25 \mathrm{~K}$ lie generally around $\pm 10 \%$ (with a tendency to $+10 \%$ ) and in January and February at around $+20 \%$, thus showing generally larger ozone mixing ratios than measured (Fig. 6, right). At $500 \pm 25 \mathrm{~K}$ the differences are generally larger than at $650 \pm 25 \mathrm{~K}$ and a stronger negative correlation is found for $\mathrm{N}_{2} \mathrm{O}$ mixing ratios greater than $200 \mathrm{ppbv}$ as also found in the evaluation for the tropics. The differences lie generally around $\pm 20 \%$ especially for midlatitude $\mathrm{N}_{2} \mathrm{O}$ mixing ratios less than $200 \mathrm{ppbv}$ (which can be attributed to air of 


\section{Midlatitudes $(\mathrm{NH})$}
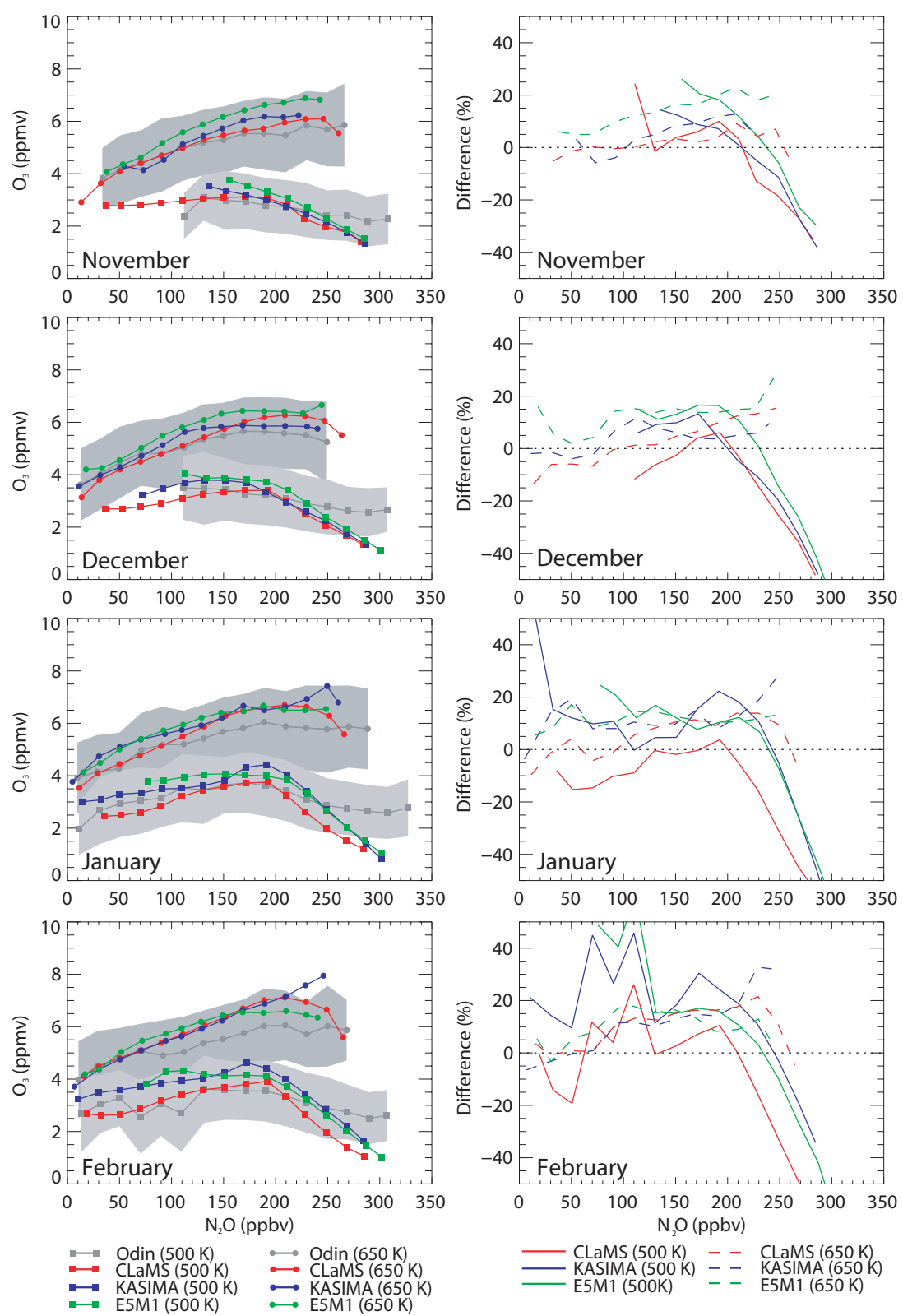

Fig. 6. Northern Hemisphere, midlatitudes. Left: Comparison of monthly averages of $\mathrm{N}_{2} \mathrm{O}$ and $\mathrm{O}_{3}$ derived from CLaMS, KASIMA and E5M1 (colored curves) with Odin/SMR (grey) at 500 $\pm 25 \mathrm{~K}$ (squares) and $650 \pm 25 \mathrm{~K}$ (circles). The grey shaded area marks the range of the standard deviations of the monthly averages of $\mathrm{O}_{3}$ derived from Odin/SMR. Right: Differences in percentage of the $\mathrm{O}_{3}$ averages of CLaMS, KASIMA and E5M1 from Odin/SMR at 500 $\pm 25 \mathrm{~K}$ (solid curves) and $650 \pm 25 \mathrm{~K}$ (dashed curves). A positive difference means an overestimation of ozone while a negative difference means an underestimation of ozone.

midlatitude and polar origin, see reference curves shown in Fig. 1 (bottom:right)). Larger differences (up to $-50 \%$ ) are found between the models and Odin/SMR for $\mathrm{N}_{2} \mathrm{O}$ mixing ratios greater than $200 \mathrm{ppbv}$. Here, differences are gradually increasing with increasing $\mathrm{N}_{2} \mathrm{O}$ due to the steeper correlation of the curves between 200 and 300 ppbv $\mathrm{N}_{2} \mathrm{O}$. These air massses can be attributed to air of tropical character as can be seen from the evaluation of the model simulations in the tropics discussed in the previous section.

At $500 \pm 25 \mathrm{~K}$ a larger amount of air of polar origin $\left(\mathrm{N}_{2} \mathrm{O}\right.$ mixing ratios less than 110 ppbv) is found in the CLaMS simulation in November and December than observed by 


\section{Polar Regions (NH)}
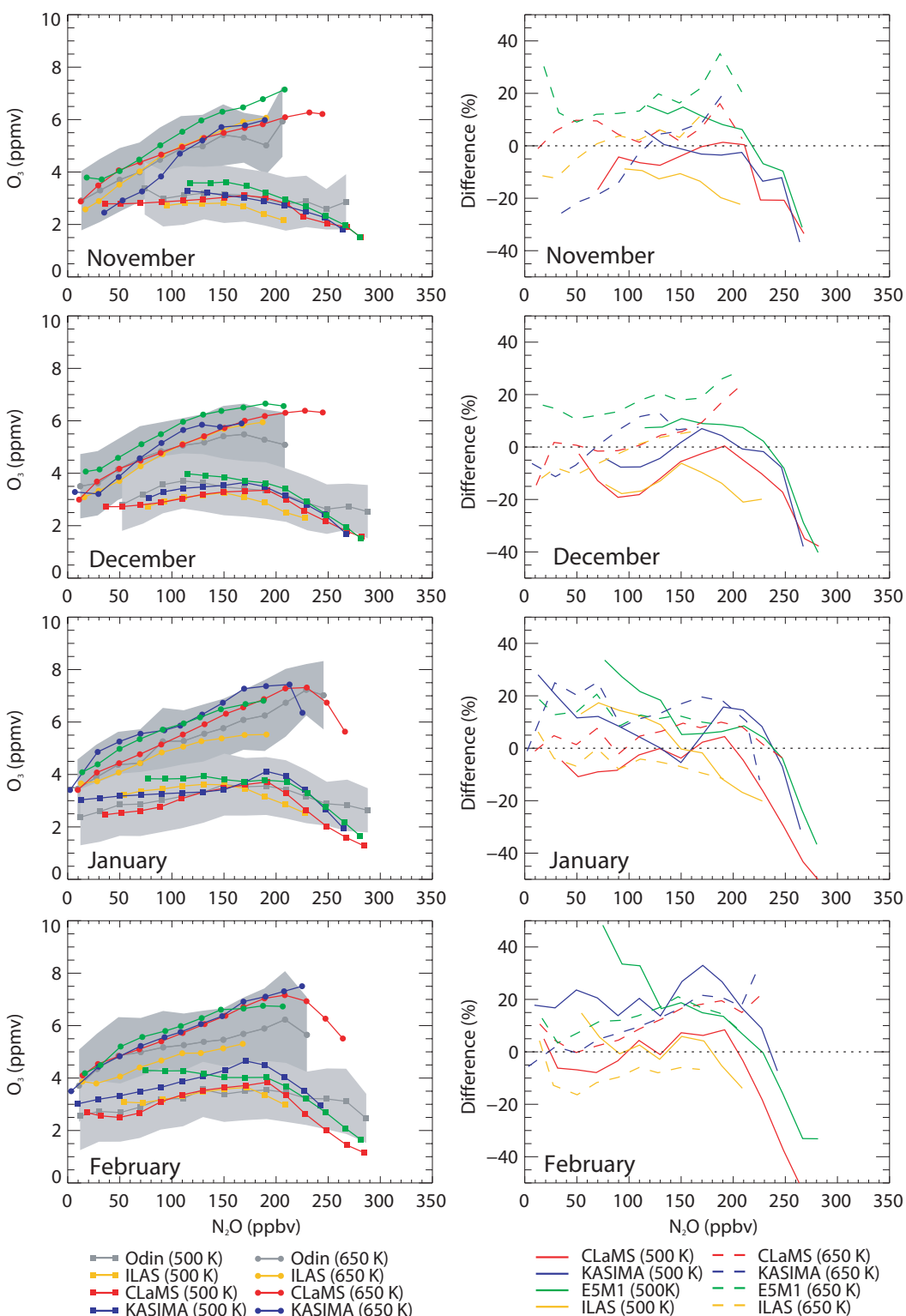

Fig. 7. Northern Hemisphere, polar regions. Left: Comparison of monthly averages of $\mathrm{N}_{2} \mathrm{O}$ and $\mathrm{O}_{3}$ derived from CLaMS, KASIMA, E5M1 and ILAS/ILAS-II (colored curves) with Odin/SMR (grey) at 500 $\pm 25 \mathrm{~K}$ (squares) and $650 \pm 25 \mathrm{~K}$ (circles). The grey shaded area marks the range of the standard deviations of the monthly averages of $\mathrm{O}_{3}$ derived from Odin/SMR. Right: Differences in percentage of the $\mathrm{O}_{3}$ averages of CLaMS, KASIMA, E5M1 and ILAS/ILAS-II from Odin/SMR at 500 $\pm 25 \mathrm{~K}$ (solid curves) and $650 \pm 25 \mathrm{~K}$ (dashed curves). A positive difference means an overestimation of ozone while a negative difference means an underestimation of ozone.

Odin/SMR (Fig. 6, left). A somewhat larger amount is also found in the KASIMA simulation in December while in E5M1 a generally lower amount is found (see next section for further details). In February large differences are found between all models and Odin/SMR at low $\mathrm{N}_{2} \mathrm{O}$ mixing ratios (Fig. 6, February). However, these differences are most likely caused by the comparably low number of data points in the bins and a high variability of the Odin/SMR measurements (mixture between inside and outside of the vortex air) which also leads to the somewhat unrealistic zigzag shape for $\mathrm{N}_{2} \mathrm{O}$ mixing ratios between 50 and 150 ppbv. 


\subsubsection{Polar regions}

Since the ILAS/ILAS-II data are available for the polar regions this data set has been included in the evaluation for the polar regions (Fig. 7). Again an agreement between CLaMS, KASIMA and E5M1 is found for $650 \pm 25 \mathrm{~K}$. The small $\mathrm{O}_{3}$ minimum found in the Odin/SMR data at $200 \mathrm{ppbv}$ $\mathrm{N}_{2} \mathrm{O}(650 \pm 25 \mathrm{~K})$ in January is most likely caused by a comparably low number of data points in the bins and a high variability of the Odin/SMR measurements. This minimum is neither found in the ILAS/ILAS-II data nor in the model simulations. At $650 \pm 25 \mathrm{~K}$ the difference lies in the range of $\pm 20 \%$. In CLaMS and E5M1 a larger amount of air of midlatitude and tropical character is found (visible as the extension of the curve to larger $\mathrm{N}_{2} \mathrm{O}$ mixing ratios).

Generally, at $650 \pm 25 \mathrm{~K}$ the differences remain the same (in the range of $\pm 20 \%$ ) for all months considered here (Fig. 7, right). Solely, the differences between ILAS/ILASII and E5M1 are somewhat larger in November for $\mathrm{N}_{2} \mathrm{O}<30$ ppbv and $\mathrm{N}_{2} \mathrm{O}>170$ ppbv (Fig. 7, right). The ILAS/ILAS-II measurements at $650 \pm 25 \mathrm{~K}$ show somewhat lower ozone mixing ratios than observed by Odin/SMR in November and December. Most likely the cause for these lower ozone mixing ratios is the fact that ILAS/ILAS-II measures closer to the pole than Odin/SMR and thus samples more air from inside the vortex and less air of midlatitude character. At $500 \pm 25 \mathrm{~K}$ differences are somewhat larger but also in the range of $\pm 20 \%$. Larger differences reaching up to $-40 \%$ are found for $\mathrm{N}_{2} \mathrm{O}$ mixing ratios greater than $200 \mathrm{ppbv}$. The data points can be attributed to air of tropical character as described in the previous two sections. However, differences are smaller here than in the midlatitudes and tropics due to the mixing of the different air masses and thus the dilution of the air of tropical character (Fig. 7, right).

Polar winter ozone loss is visible at $500 \pm 25 \mathrm{~K}$ from January on by an inflection of the curves and thus a change of slope to negatively correlated and an extension to lower $\mathrm{N}_{2} \mathrm{O}$ mixing ratios (Fig. 7, left, January). The inflection of the curves is generally found around 150 to $200 \mathrm{ppbv} \mathrm{N}_{2} \mathrm{O}$. Thereby, the inflection is shifted to lower $\mathrm{N}_{2} \mathrm{O}$ mixing ratios with increasing ozone destruction. Differences in the location of the inflection between different data sets cannot only occur due to differences caused by considering data sets of different years but also when the data sets do not cover the same latitude region and e.g. measure a different amount of air from within the vortex. In the Odin/SMR data this inflection between ILAS/ILAS-II and Odin/SMR is found at 190 ppbv $\mathrm{N}_{2} \mathrm{O}$ and ILAS/ILAS-II at 150 ppbv. This difference in the inflection is most probably caused by differences in ozone loss in the winters 1996/1997 and 2002/2003 (all months shown here are taken from ILAS measurements, thus from 1996/1997). In the CLaMS, and KASIMA simulation the inflection is found at the same location as Odin/SMR. In the E5M1 simulation the inflection is found at somewhat higher $\mathrm{N}_{2} \mathrm{O}$ mixing ratios $(210 \mathrm{ppbv}$ instead of $190 \mathrm{ppbv}$
$\mathrm{N}_{2} \mathrm{O}$ ) and the $\mathrm{O}_{3}$ mixing ratios are not as low as measured by Odin/SMR. The $\mathrm{O}_{3}$ mixing ratios in E5M1 are rather increasing towards February which indicates that polar winter ozone loss is underestimated. A slight underestimation of polar ozone loss is also found in the KASIMA simulation since the $\mathrm{O}_{3}$ mixing ratios are not reaching as low values as CLaMS or Odin/SMR, but for the CLaMS simulation a satisfactory agreement is found. An underestimation of polar ozone loss has also been observed in other CCMs, e.g. in the CCM WACCM (Whole-Atmosphere Community Climate Model). Tilmes et al. (2007) showed that Arctic ozone loss in spring is severely underestimated by WACCM. The main reason for the underestimation of Arctic $\mathrm{O}_{3}$ loss in WACCM reported by Tilmes et al. (2007) is an overestimation of polar temperatures, a problem that does not occur in a CTM (like CLaMS) and to a lesser extent in a nudged global models (like KASIMA and E5M1). A second important problem is the quality of the simulation of the strength, sharpness and location of the transport barrier at the vortex edge (Sankey and Shepherd, 2003; Tilmes et al., 2007), which is an issue for both CTM and CCM. Indeed, a WACCM simulation at higher horizontal resolution (Tilmes et al., 2009) yields a substantially improved chemical ozone loss in the Arctic.

While the underestimation of ozone loss in KASIMA is most probably caused only by a underestimation of the chemistry, in E5M1 the underestimation of ozone loss is most probably caused by both an underestimation of the chemistry as well as descent since the typical low $\mathrm{O}_{3}$ mixing ratios found at low $\mathrm{N}_{2} \mathrm{O}$ mixing ratios $(<50 \mathrm{ppbv})$, thus an extension of the curve to lower $\mathrm{N}_{2} \mathrm{O}$ values, are not found in the E5M1 simulation. At $650 \pm 25 \mathrm{~K}$ differences in the averaged $\mathrm{O}_{3}$ mixing ratios are generally within $\pm 20 \%$. A rather reasonable agreement with differences up to $-40 \%$ is found for $\mathrm{N}_{2} \mathrm{O}$ mixing ratios greater than 250 ppbv. In both levels the $\mathrm{N}_{2} \mathrm{O} / \mathrm{O}_{3}$ distribution remains almost unchanged in all data sets from January to February.

\subsection{Assessment on different data sets used for a model evaluation}

In the following we will repeat the evaluation for the polar regions using the ILAS/ILAS-II data set as the reference data set to assess how the results change if this data set is used instead of Odin/SMR. The general characteristics of the monthly averages derived from CLaMS, KASIMA and E5M1 are in agreement with the monthly averages derived from ILAS/ILAS-II measurements (Fig. 8).

Generally the difference between the ILAS/ILAS-II data and the CLaMS, KASIMA and E5M1 results are similar to the differences derived using the Odin/SMR data set as a reference. However, somewhat larger differences are found for CLaMS, KASIMA and E5M1 in November in December at $500 \pm 25 \mathrm{~K}$ compared to the evaluation using Odin/SMR as the reference (Fig. 8 compared to Fig. 7, right). Further, somewhat larger differences are also found for all 
three models in January and February at $650 \pm 25 \mathrm{~K}$ and at $500 \pm 25 \mathrm{~K}$ since at this level lower $\mathrm{O}_{3}$ mixing ratios were measured by ILAS/ILAS-II than by Odin/SMR. This is due to the fact that ILAS/ILAS-II measurements are focused on the polar regions and thus less air from outside the vortex (air that contains larger amounts of ozone) was sampled. Further, due to the focus of ILAS/ILAS-II on the polar regions and the usage of solar occultation technique, the $\mathrm{N}_{2} \mathrm{O} / \mathrm{O}_{3}$ curves derived from ILAS/ILAS-II extend over a smaller $\mathrm{N}_{2} \mathrm{O}$ range than the curves derived from Odin/SMR (Fig. 8 compared to Fig. 7).

Furthermore, the large differences which were found in the evaluation of CLaMS, KASIMA and E5M1 with Odin/SMR at $\mathrm{N}_{2} \mathrm{O}$ mixing ratios greater than $200 \mathrm{ppbv}$ due to air of tropical character are not found here since such air masses are not measured by ILAS/ILAS-II (Fig. 8, left). Thus, it seems, that the models show a stronger influence of air of tropical and midlatitude character in the polar regions.

Using the ILAS/ILAS-II data set as reference for the model evaluation shows slight deviations in the absolute differences compared to than Odin/SMR is used as reference. However, the main result, that CLaMS, KASIMA and E5M1 are in agreement $( \pm 20 \%)$ with the observations is also supported by the evaluation using ILAS/ILAS-II data as reference. Thus, both data set are suitable for a model evaluation. Of course, the ILAS/ILAS-II data set can only be used for an evaluation study for the polar regions. If the entire hemisphere is to be analysed or a separation into latitude regimes is envisaged one needs to use the Odin/SMR data sets. Further, there are also other satellite measurements which can be used for deriving monthly averages of $\mathrm{N}_{2} \mathrm{O}$ and $\mathrm{O}_{3}$ and thus can be used for an evaluation study as presented here. Furthermore, we also would recommend to take all available data sets derived from satellite measurements into account for a model evaluation study.

\subsection{Assessment on different vertical resolutions used in model simulations}

To asses the impact of different vertical resolutions of the model simulation we compare the E5M1 simulation in T42L90MA resolution used in the evaluation study described in the previous sections with an E5M1 simulation with a T42L39MA resolution (Fig. 9, NH, all latitudes). Generally, the shape of the curves are similar, however differences of the T42L39MA data to Odin/SMR are somewhat larger, especially at $500 \pm 25 \mathrm{~K}$ than for the high resolution simulation. At $500 \pm 25 \mathrm{~K}$ ozone mixing ratios are generally higher in the T42L39MA simulation than in the T42L90MA simulation (November and December entire curve, January and February $\mathrm{N}_{2} \mathrm{O}$ values greater than $200 \mathrm{ppbv}$ ). That E5M1 underestimates the polar ozone destruction during winter is a general problem of the model, however, much better results are derived with the E5M1 simulation with a higher vertical resolution. In the T42L39MA simulation the slope change is found at $230 \mathrm{ppbv}(500 \pm 25 \mathrm{~K}$, January) while it is found at $210 \mathrm{ppbv}$ in the T42L90MA simulation, which is almost in agreement with Odin/SMR where the slope change is found at 190 ppbv (Fig. 9, left, January).

At $500 \pm 25 \mathrm{~K}$, differences in ozone mixing ratios between E5M1 and Odin/SMR increase with decreasing $\mathrm{N}_{2} \mathrm{O}$ towards February. In February, at 70 ppbv $\mathrm{N}_{2} \mathrm{O} 4.2$ ppmv $\mathrm{O}_{3}$ are derived from both E5M1 simulations instead of $2.7 \mathrm{ppmv}$ as derived from Odin/SMR observations (a difference of $1.7 \mathrm{ppmv}$ and thus up to $65 \%$ more ozone in both simulations).

Another important difference is that in the simulation with lower resolution some artifacts are occurring, particularly noticeable in the curve at $650 \pm 25 \mathrm{~K}$ in December. There is a peak in $\mathrm{O}_{3}$ at $\mathrm{N}_{2} \mathrm{O}$ mixing ratios between $230 \mathrm{ppbv}$ and 280 ppbv. This peak most likely occurs because of the quasibiennial oscillation (QBO) which is treated differently in both simulations. In the E5M1 T42L39MA simulation the QBO is nudged while in the E5M1 T42L90MA simulation the QBO develops freely.

\subsection{Average differences}

An average of the differences of the monthly averaged $\mathrm{O}_{3}$ mixing ratios between CLaMS, KASIMA and E5M1 and Odin/SMR has been calculated for each month to give an overview of the performance of the models for each month of the year. While the KASIMA and E5M1 simulation cover an entire year the simulation of CLaMS covers only the winter period (November to March) and only for the Northern Hemisphere. The calculation of the average difference has been performed for the separation into the three latitude regimes: high latitude $\left(60^{\circ}-90^{\circ}\right)$, midlatitude $\left(30^{\circ}-60^{\circ}\right)$ and low latitudes $\left(0^{\circ}-30^{\circ}\right)$. Since the CLaMS simulation focused on the polar regions the average of the differences has not been calculated for the low latitudes. Further, since ILAS/ILAS-II measurements only cover the polar regions the average of the differences of ILAS/ILAS-II have been calculated for the polar regions.

\subsubsection{Northern Hemisphere}

An agreement between both satellite instruments, Odin/SMR and ILAS/ILAS-II, is found at $500 \pm 25 \mathrm{~K}$ (Fig. 10, solid lines). Differences in $\mathrm{O}_{3}$ mixing ratios are lower than $\pm 20 \%$. At $650 \pm 25 \mathrm{~K}$ differences are about the same, but increase to $35 \%$ for the summer months (May to September). Thus, for the summer months only a reasonable agreement between ILAS/ILAS-II and Odin/SMR is found. Differences in $\mathrm{O}_{3}$ mixing ratios between the models and Odin/SMR are generally within $\pm 20 \%$, but reach at some occasions up to $40 \%$ especially in the polar regions during summer months. Differences exceeding $20 \%$ are found in the polar regions at $500 \pm 25 \mathrm{~K}$ from February to September (KASIMA, up to $40 \%)$ and in April (E5M1, 25\%) as well as at $650 \pm 25 \mathrm{~K}$ in May and August (E5M1, 25 and 30\%). In the tropical 


\section{Polar Regions (NH)}
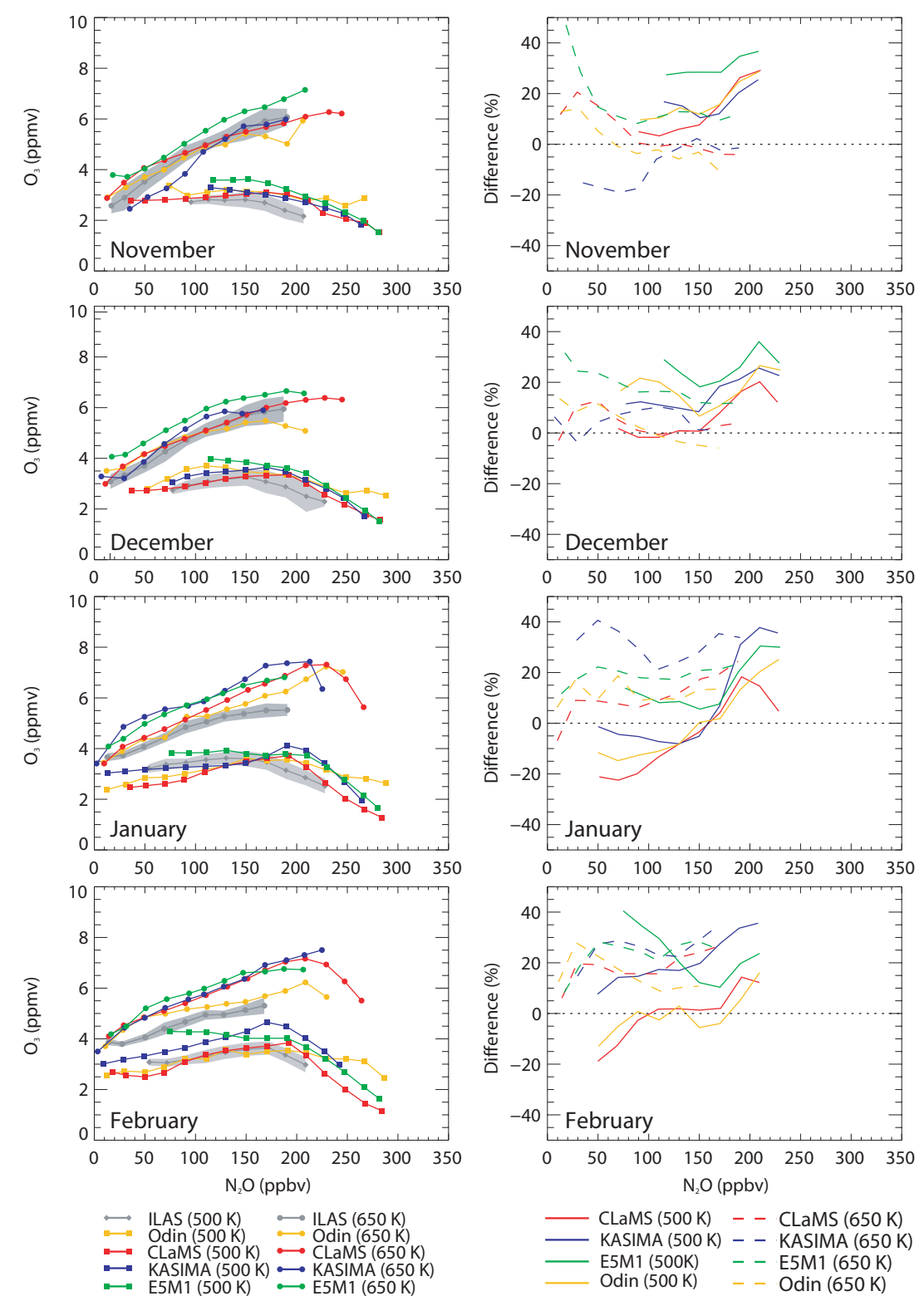

Fig. 8. As Fig. 7, but using ILAS/ILAS-II as the reference (Northern Hemisphere polar regions). Left: Comparison of monthly averages of $\mathrm{N}_{2} \mathrm{O}$ and $\mathrm{O}_{3}$ derived from CLaMS, KASIMA, E5M1 and Odin/SMR (colored curves) with ILAS/ILAS-II (grey) at 500 $\pm 25 \mathrm{~K}$ (squares) and $650 \pm 25 \mathrm{~K}$ (circles). The grey shaded area marks the range of the standard deviations of the monthly averages of $\mathrm{O}_{3}$ derived from ILAS/ILAS-II. Right: Differences in percentage of the $\mathrm{O}_{3}$ averages of CLaMS, KASIMA, E5M1, and Odin/SMR from ILAS/ILAS-II at $500 \pm 25 \mathrm{~K}$ (solid curves) and $650 \pm 25 \mathrm{~K}$ (dashed curves). A positive difference means an overestimation of ozone while a negative difference means an underestimation of ozone.

regions, differences exceeding $20 \%$ are found from April to October (KASIMA, up to $30 \%$ ) and from February to September (E5M1, up to 25\%). From the CLaMS simulation the summer months are not available since the simulation covers only the winter months, thus, we do not know whether differences higher than $20 \%$ are also found in CLaMS (Fig. 10, bottom). Nevertheless, the best agreement between CLaMS, KASIMA and E5M1 is found for the midlatitude region where differences between the models and Odin/SMR over the entire year are lower than $\pm 20 \%$ (Fig. 10, middle). 


\section{All Latitudes $(\mathrm{NH})$}
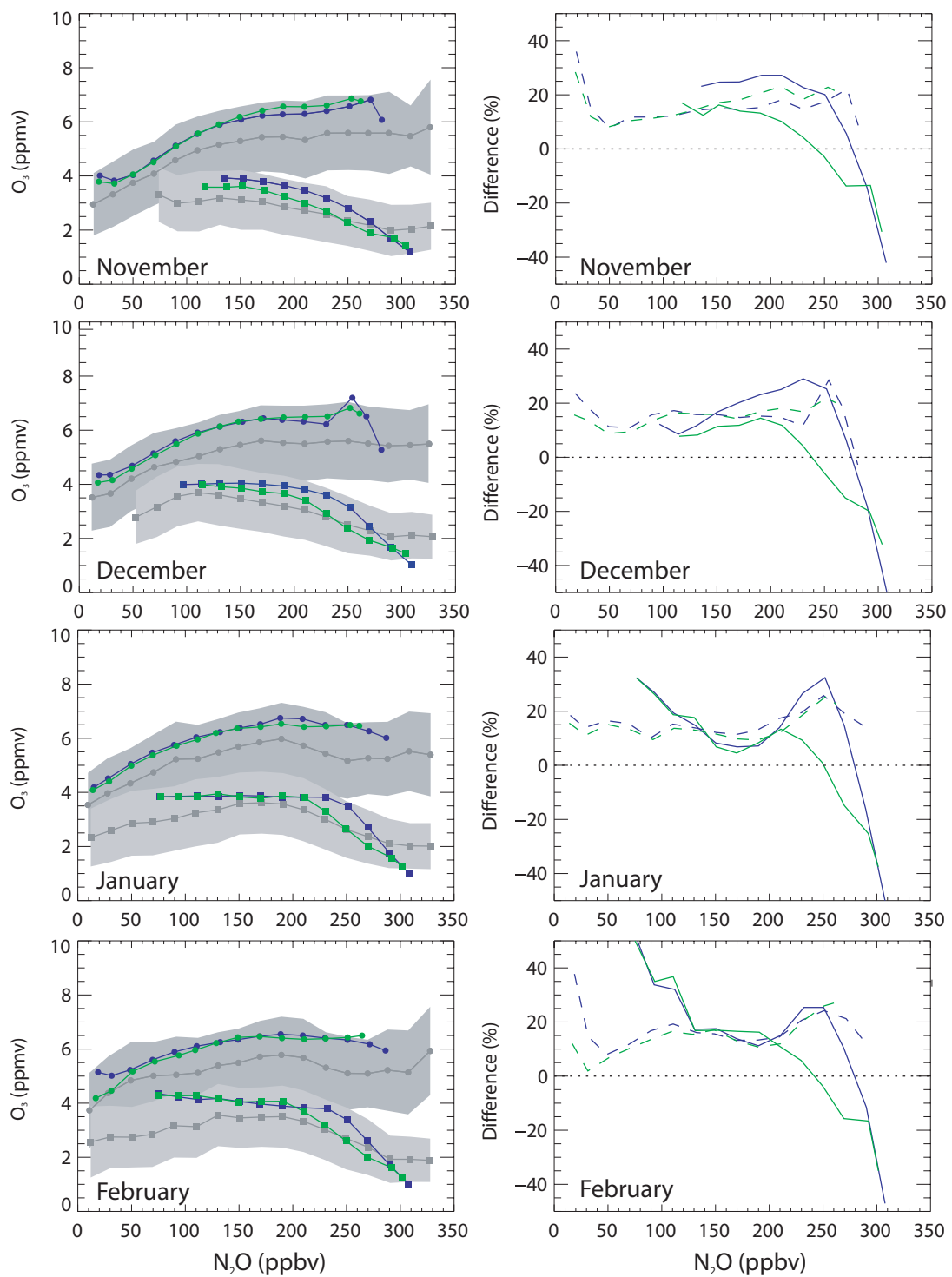

$\because \operatorname{Odin}(500 \mathrm{~K}) \quad \because \operatorname{Odin}(650 \mathrm{~K})$

$\longrightarrow \mathrm{E} 5 \mathrm{M} 1-\mathrm{L} 39(500 \mathrm{~K}) \longrightarrow \mathrm{E} 5 \mathrm{M} 1-\mathrm{L} 39(650 \mathrm{~K})$

$\longrightarrow$ E5M1-L90 (500 K) —E5M1-L90 (650 K)

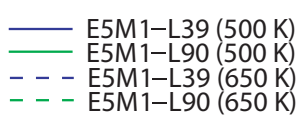

Fig. 9. As Figure 4, but showing (left) the impact of different vertical resolutions (Northern Hemisphere). Left: The comparison of monthly averages of $\mathrm{N}_{2} \mathrm{O}$ and $\mathrm{O}_{3}$ derived from E5M1 T42L90MA and E5M1 T42L39MA simulation (colored curves) with Odin/SMR (grey) at $500 \pm 25 \mathrm{~K}$ (squares) and $650 \pm 25 \mathrm{~K}$ (circles). The grey shaded area marks the range of the standard deviations of the monthly averages of $\mathrm{O}_{3}$ derived from Odin/SMR. Right: Differences in percentage of the $\mathrm{O}_{3}$ averages of E5M1 T42L90MA and E5M1 T42L39MA simulation from Odin/SMR at $500 \pm 25 \mathrm{~K}$ (solid curves) and $650 \pm 25 \mathrm{~K}$ (dashed curves). A positive difference means an overestimation of ozone while a negative difference means an underestimation of ozone.

\subsubsection{Southern Hemisphere}

Differences in the Southern Hemisphere are similar to the differences in the Northern Hemisphere (Fig. 11). For the polar regions, an agreement is found between ILAS/ILAS-
II and Odin/SMR at $500 \pm 25 \mathrm{~K}$ for all months except for October where differences increase up to $-40 \%$ (Southern Hemisphere spring). This difference is caused by the fact that ILAS/ILAS-II measured at that time of the year very close to the pole and thus mainly air from inside the polar 

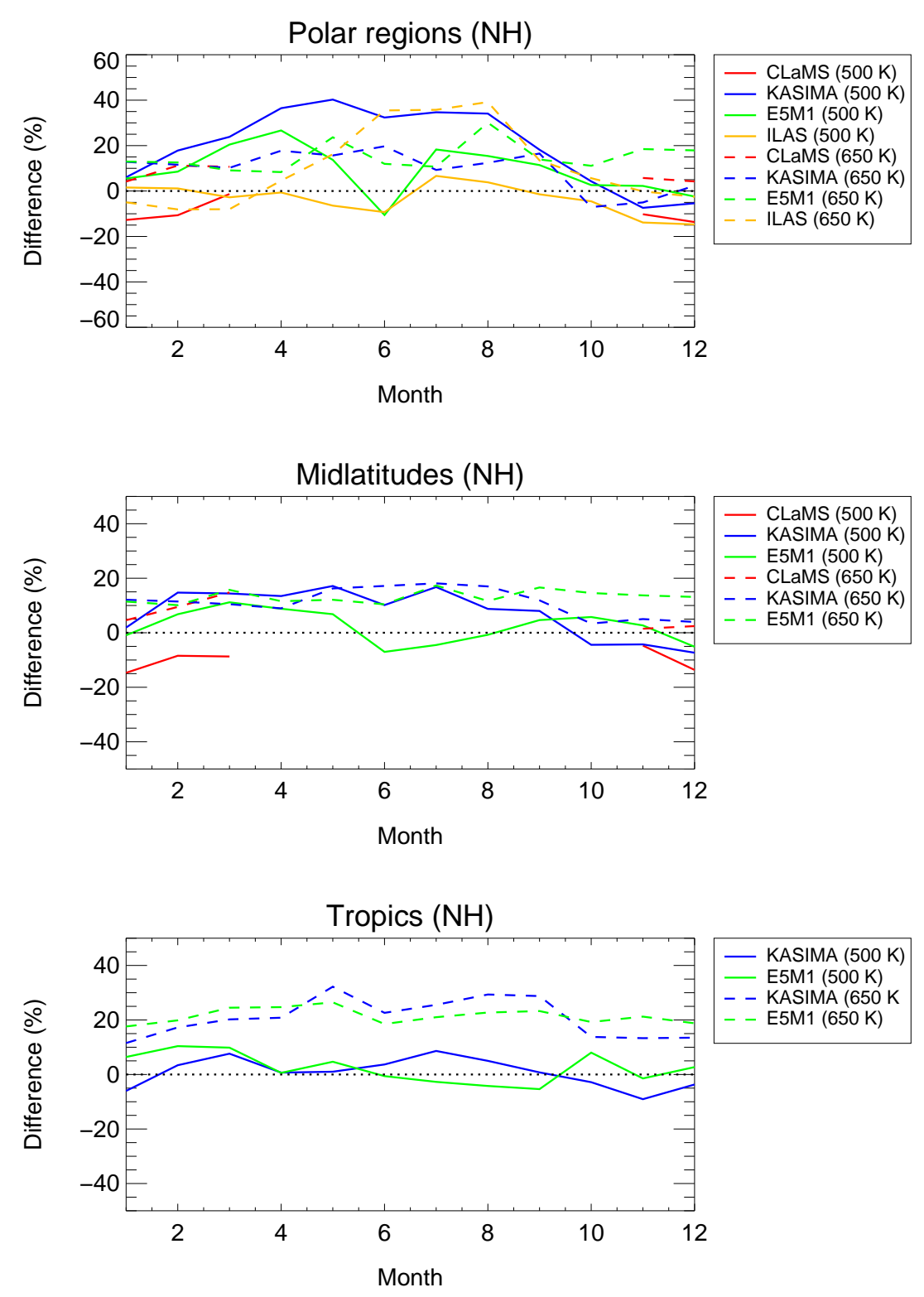

Fig. 10. The averaged differences in percentage between the monthly averaged $\mathrm{O}_{3}$ mixing ratios derived from the model simulations of CLaMS (red), KASIMA (blue), E5M1 (green) and ILAS/ILAS-II (yellow) measurements, respectively, from the monthly averaged $\mathrm{O}_{3}$ mixing ratios derived from Odin/SMR at $500 \pm 25 \mathrm{~K}$ (solid curves) and $650 \pm 25 \mathrm{~K}$ (dashed curves) are shown for every month of the year and separated by latitude region (Northern Hemisphere).

vortex where at that time low $\mathrm{O}_{3}$ mixing ratios prevail because of chemical $\mathrm{O}_{3}$ loss. At $650 \pm 25 \mathrm{~K}$ an agreement is found between ILAS/ILAS-II and Odin/SMR (differences within $\pm 20 \%$ ) for all months except January where the difference reaches $+40 \%$ (Fig. 11, top). As for the Northern Hemisphere the best agreement between the models and Odin/SMR is found for the midlatitudes with differences less than $+20 \%$. Solely, in the E5M1 simulation at $500 \pm 25 \mathrm{~K}$ differences up to $-20 \%$ are reached in October and November (Fig. 11, middle panel). This "peak" in the E5M1 sim- ulation is also found in the polar regions and can be attributed to an underestimation of chemical ozone destruction in the ozone hole region. Thus, in the $55 \mathrm{M} 1 \mathrm{O}_{3}$ mixing ratios as low as measured under ozone hole conditions are not reached (Fig. 11, top). In E5M1 (not shown) the minimum $\mathrm{O}_{3}$ values ( $1 \mathrm{ppmv}$ ) measured by Odin/SMR are reached, however, only for $\mathrm{N}_{2} \mathrm{O}$ mixing ratios (50-110 ppbv) higher than in the Odin/SMR observations (10-120 ppbv). This will result in an underestimation of column $\mathrm{O}_{3}$ loss in the ozone hole. Underestimation of chemical ozone loss in 

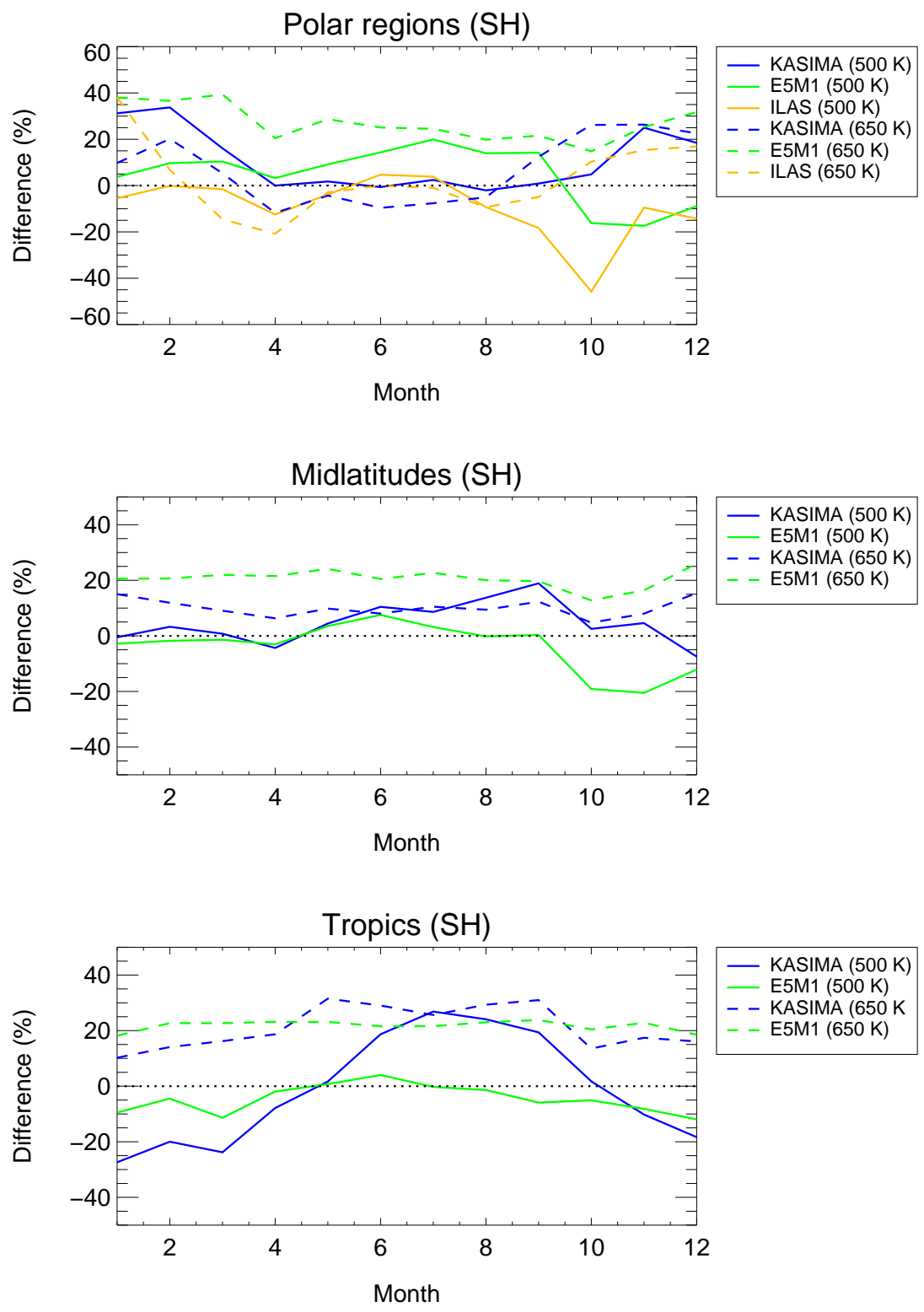

Fig. 11. The averaged differences in percentage between the monthly averaged $\mathrm{O}_{3}$ mixing ratios derived from the model simulations of KASIMA (blue) and E5M1 (green) and ILAS/ILAS-II (yellow) measurements, respectively, from the monthly averaged $\mathrm{O}_{3}$ mixing ratios derived from Odin/SMR measurements at $500 \pm 25 \mathrm{~K}$ (solid curves) and $650 \pm 25 \mathrm{~K}$ (dashed curves) are shown for every month of the year and separated by latitude region (Southern Hemisphere).

the Southern Hemisphere polar regions were recently also reported for the models WACCM (Tilmes et al., 2007) and E39/C (Lemmen et al., 2006).

In the polar regions the differences between Odin/SMR and KASIMA as well as E5M1 lie generally between $-10 \%$ and $+30 \%$ (Fig. 11, top). Solely, differences up to $-20 \%$ are found for the E5M1 simulation at $500 \pm 25 \mathrm{~K}$ in October as discussed above and up to $30 \%$ in September at $650 \pm 25 \mathrm{~K}$. In the tropics, the differences of KASIMA and E5M1 show the same shape with somewhat larger differ- ences in the KASIMA simulation at $500 \pm 25 \mathrm{~K}$. However, differences lie generally within $\pm 25 \%$ but increase gradually from $-20 \%$ to $+20 \%$ in July and decrease to $-20 \%$ by December (Fig. 11, bottom).

\section{Conclusions}

We apply the method suggested by Proffitt et al. (2003) to evaluate atmospheric photochemical models. Proffitt et al. 
(2003) used tracer-tracer correlations in a somewhat different way than done in the classical $\mathrm{O}_{3}$-tracer correlation method (e.g Proffitt et al., 1993; Tilmes et al., 2004), namely by calculating averages of $\mathrm{N}_{2} \mathrm{O}$ and $\mathrm{O}_{3}$, thereby reducing $\mathrm{O}_{3}$ variability caused by latitudinal transport processes. Here, monthly averages of $\mathrm{N}_{2} \mathrm{O}$ and $\mathrm{O}_{3}$ were derived from ILAS/ILAS-II and Odin/SMR observations. The data were binned by potential temperature and then averaged over a fixed interval of $\mathrm{N}_{2} \mathrm{O}$ resulting in families of $\mathrm{N}_{2} \mathrm{O} / \mathrm{O}_{3}$ curves. Based on these data sets of monthly averages of $\mathrm{N}_{2} \mathrm{O}$ and $\mathrm{O}_{3}$ we evaluated the CTMs CLaMS and KASIMA as well as the CCM E5M1. As a condition for model performance, we require that the families of curves resulting from the data sets of monthly averaged $\mathrm{N}_{2} \mathrm{O}$ and $\mathrm{O}_{3}$ are reproduced by the models within the variability of the monthly averages deduced from observations. Note that therefore a compact $\mathrm{O}_{3}$-tracer relationship is here not required. Using data from Odin/SMR allows to perform the model evaluation for the entire hemisphere as well as separated into the latitude regions high, mid and low latitudes. Using additionally the ILAS/ILASII data set as the reference for the polar latitudes it could be shown that this data set is also adequate for a model evaluation, although it is restricted to the polar latitudes since from ILAS/ILAS-II only measurements for this region are available.

In general, the data sets derived from the model simulations were in agreement with the data set derived from Odin/SMR. Differences between the averaged $\mathrm{O}_{3}$ mixing ratios derived from CLaMS, KASIMA and E5M1 and $\mathrm{O}_{3}$ from Odin/SMR were calculated. These differences were generally in the range of $\pm 20 \%$ considering the entire hemisphere $\left(0-90^{\circ}\right)$. Larger differences up to $\pm 40 \%$ were found at $\mathrm{N}_{2} \mathrm{O}$ mixing ratios greater than $250 \mathrm{ppbv}$ (tropical air and air of tropical character). A clear underestimation of ozone loss in polar winter is obvious at $500 \pm 25 \mathrm{~K}$ in the KASIMA and E5M1 simulations. The overestimation of ozone in KASIMA is most likely caused by an underestimation of chemical polar winter ozone loss while in E5M1 most likely also descent in winter and early spring is underestimated since the typical low $\mathrm{O}_{3}$ mixing ratios at low $\mathrm{N}_{2} \mathrm{O}$ mixing ratios seen in the averages of Odin/SMR and ILAS/ILAS-II were not simulated. The underestimation of ozone loss in E5M1 is a general model difficiency, however, the model results can be improved significantly if a higher vertical resolution is used as was shown comparing the E5M1 T42L39MA simulation with the T42L90MA simulation. Recent analyses of chemical ozone loss in the polar regions show that also other chemistry climate models not only significantly underestimate polar ozone loss (Lemmen et al., 2006; Tilmes et al., 2007) but also underestimate the variability of Arctic polar ozone loss (Hegglin and Shepherd, 2007).

For the evaluation separated into latitude regimes (Fig. 5Fig. 7) the best agreement between models and Odin/SMR was found for the midlatitude regions and the largest differences for the tropics, but only at the $500 \pm 25 \mathrm{~K}$ level. This difference between models and Odin/SMR is partly caused by the large vertical $\mathrm{O}_{3}$ gradients occurring in the tropical regions which cannot entirely be resolved by the rather coarse vertical resolution of Odin/SMR of $3 \mathrm{~km}$, but probably also to some part by inaccuracies in the model simulations of transport in the tropical stratosphere. To understand this difference between the models and Odin/SMR in detail further satellite data sets have to be taken into account which was however beyond the scope of this study.

Considering averages of the differences of the monthly averaged $\mathrm{O}_{3}$ mixing ratios for each month over an entire year, ILAS/ILAS-II and Odin/SMR were generally in agreement and differences were within $\pm 20 \%$. However, differences reaching up to $\pm 40 \%$ where found in the Northern Hemisphere during summer and in the Southern Hemisphere during winter. Comparing these averaged differences of $\mathrm{O}_{3}$ mixing ratios derived from the model simulations with Odin/SMR the best agreement was found in both hemispheres for the midlatitudes. Differences were generally within $\pm 20 \%$ for both hemispheres and all latitude regimes. Larger differences were found occasionally in both hemispheres for the summer months in the tropics and polar regions. Differences reached up to $40 \%$ (KASIMA) at $500 \pm 25 \mathrm{~K}(\mathrm{NH})$ and up to $40 \%(\mathrm{E} 5 \mathrm{M} 1)$ at $650 \mathrm{~K}(\mathrm{SH})$ in the polar regions. In the tropics the differences in the summer months reached up to 30\% (KASIMA and E5M1) at $500 \pm 25 \mathrm{~K}$ and $650 \pm 25 \mathrm{~K}$ ( $\mathrm{NH}$ and $\mathrm{SH}$ ). The differences in the tropics might be due to both measurement and model deficiencies. Since the CLaMS simulation was only performed for the winter months no evaluation of the summer months could be performed here. Nevertheless, the method presented here presents a promising tool for the evaluation of atmospheric chemical models like CTMs and CCMs and was successfully applied to evaluate CLaMS, KASIMA and E5M1.

Acknowledgements. We are grateful to the European Space Agency (ESA) for providing the Odin/SMR data. Odin is a Swedish led project funded jointly by Sweden (SNSB), Canada (CSA), Finland (TEKES), and France (CNES) and the European Space Agency (ESA). The Improved Limb Atmospheric Spectrometer (ILAS and ILAS-II) were were developed by the Japanese Ministry of Environment (MOE) and were operated by the Japan Aerospace Exploration Agency (JAXA). The ILAS/ILAS-II data was processed at the ILAS and ILAS-II Data Handling Facility, National Institute of Environmental Studies (NIES), Japan. We would like to thank the UK Met Office (UKMO) and European Center for Medium Range Weather Forecasts (ECMWF) for providing their meteorological analyses. We also would like to thank P. Achtert for helping with the graphic editing and the anonymous reviewers for helpful comments. We are also grateful to the Swedish Research Council for funding F. Khosrawi.

Edited by: W. Lahoz 


\section{References}

Bian, H. and Prather, M.: Fast-J2: Accurate simulation of stratospheric photolysis in global chemical models, J. Atmos. Chem., 41, 281-296, 2002.

Brühl, C. and Crutzen, P. J.: $\mathrm{NO}_{\mathrm{x}}$-catalyzed ozone destruction and $\mathrm{NO}_{\mathrm{x}}$ activation at midlatitudes to high latitudes as the main cause of the spring to fall stratospheric ozone decline in the Northern Hemisphere, J. Geophys. Res., 105, 12163-12168, 2000.

Buchholz, J.: Simulations of physics and chemistry of polar stratospheric clouds with a general circulation model, Ph.d. thesis, Johannes Gutenberg University Mainz, 2005.

Dupuy, E., Walker, K. A., Kar, J., Boone, C. D., McElroy, C. T., Bernath, P. F., Drummond, J. R., Skelton, R., McLeod, S. D., Huges, R. C., Nowlan, C. R., Dufour, D. G., Zou, J., Nichitu, F., Strong, K., Baron, P., Bevilaqua, R. M., Blumenstock, T., Bodeker, G. E., Borsdorff, T., Bourassa, A. E., Bovensmann, H., Boyd, I. S., Bracher, A., Borgniez, C., Burrows, J. P., Catoire, V., Ceccherini, S., et al.: Validation of ozone measurements from the Atmospheric Chemistry Experiment (ACE), Atmos. Chem. Phys. Discuss., 9, 287-343, 2009, http://www.atmos-chem-phys-discuss.net/9/287/2009/.

Ejiri, M. K., Terao, Y., Sugita, T., Nakajima, H., Yokota, T., Toon, G. C., Sen, B., Wetzel, G., Oelhaf, H., Urban, J., Murtagh, D., Irie, H., Saitoh, N., Tanaka, T., Kanzawa, H., Shiotani, M., Kobayashi, H., and Sasano, Y.: Validation of ILAS-II V1.4 nitrous oxide and methane profiles, J. Geophys. Res., 111, D22S90, doi:10.1029/2005JD006449, 2006.

Eyring, V., Butchart, N., Waugh, D. W., Akiyoshi, H., Austin, J., Bekki, S., Bodeker, G. E., Boville, B. A., Brühl, C., Chipperfield, M. P., Cordero, E., Dameris, M., Deushi, M., Fioletov, V. E., Frith, S. M., Garcia, R. R., Gettelman, A., Giorgetta, M. A., Grewe, V., Jourdain, L., Kinnison, D. E., Mancini, E., Manzini, E., Marchand, M., Marsh, D. R., Nagashima, T., Nielsen, E., Newman, P. A., Pawson, S., Pitari, G., Plummer, D. A., Rozanov, E., Schraner, M., Shepherd, T. G., Shibata, K., Stolarski, R. S., Struthers, H., Tian, W., and Yoshiki, M.: Assessment of temperature, trace species and ozone in chemistryclimate simulations of the recent past, J. Geophys. Res., 111, D22 308, 10.1029/2006JD007327, 2006.

Eyring, V., Waugh, D. W., Bodeker, G. E., Cordero, E., Akiyoshi, H., Austin, J., Beagley, S. R., Boville, B. A., Braesicke, P., Brühl, C., Butchart, N., Chipperfield, M. P., Dameris, M., Deckert, R., Deushi, M., Frith, S. M., Garcia, R. R., Gettelmann, A., Giorgetta, M. A., Kinneson, D. E., Mancini, E., Manzini, E., Marsh, D. R., Matthes, S., Nagashima, T., Newman, P. A., Nielson, J. E., Pawson, S., Pitari, G., Plummer, D. A., Rozanov, R., Schraner, M., Scinocca, J. F., Semeniuk, K., Shepherd, T. G., Shibata, K., Steil, B., Stolarski, R. S., Tian, W., and Yoshiki, M.: Multimodel projections of stratospheric ozone in the 21st century, J. Geophys. Res., 112, D16303, doi:10.1029/2006JD008332, 2007.

Fahey, D. W., Solomon, S., Kawa, S. R., Loewenstein, M., Podolske, J. R., Strahan, S. E., and Chan, K. R.: A diagnostic for denitrification in the winter polar stratospheres, Nature, 345, 698-702, 1990.

Farman, J. C., Murgatroyd, R. J., Silnickas, A. M., and Thrush, B. A.: Ozone photochemistry in the Antarctic stratosphere in summer, Q. J. Roy. Meteor. Soc., 111, 1013-1025, 1985.

Frisk, U., Gastrom, M., Ala-Laurinaho, J., Andersson, S., Berges, J. C., Chabaud, J. P., Dahlgren, M., Emrich, A., Florin, G.,
Fredrixon, M., Gaier, T., Haas, R., Hjalmarsson, T. H. A., Jakobsson, B., Jukkala, P., Kildal, P. S., Kollberg, E., Lecacheux, J. L. A., Lehikoinen, P., Lehto, A., Mallat, J., Marty, C., Michet, D., Narbonne, J., Nexon, M., Olberg, M., Olofsson, A. O. H., Olofsson, G., Origne, A., Petersson, M., Piirone, P., Pouliquen, D., Ristorcelli, I., Rosolen, C., Rouaix, G., Raisanen, A. V., Serra, G., Sjoberg, F., Stenmark, L., Torchinsky, S., Tuovinen, J., Ullberg, C., Vinterhav, E., Wadefalk, N., Zirath, H., Zimmermann, P., and Zimmermann, R.: The Odin satellite: I. Radiometer design and test, Astron. Astrophys., 403, 27-34, 2003.

Giorgetta, M. A., Manzini, E., Roeckner, E., Esch, M., and Bengtsson, L.: Climatology and forcing of the quasi-biennial oscillation in the MAECHAM5 model, J. of Clim., 19, 3882-3901, 2006.

Goutail, F., Pommereau, J.-P., Lefèvre, F., van Roozendael, M., Anderson, S. B., Kaastad Hoiskar, B.-A., Dorkhov, V., Kyrö, E., Chipperfield, M. P., and Feng, W.: Early unusual ozone loss during the Arctic winter 2002/2003 compared to other winters, Atmos. Chem. Phys., 5, 665-677, 2005.

Griesfeller, A., von Clarmann, T., Griesfeller, J., Höpfner, M., Milz, M., Nakajima, H., Steck, T., Sugita, T., Tanaka, T., and Yokota, T.: Intercomparison of ILAS-II Version 1.4 and Version 2 target parameters with MIPAS-Envisat measurements, Atmos. Chem. Phys., 8, 825-843, 2008.

Grooß, J.-U., Günther, G., Müller, R., Konopka, P., Bausch, S., Schlager, H., Voigt, C., Volk, C. M., and Toon, G. C.: Simulation of denitrification and ozone loss for the Arctic winter 2002/2003, Atmos. Chem. Phys., 5, 1437-1448, 2005.

Hegglin, M. I. and Shepherd, T. G.: $\mathrm{O}_{3}-\mathrm{N}_{2} \mathrm{O}$ correlations from Atmospheric Chemistry Experiment: Revisiting a diagnostic of transport and chemistry in the stratosphere, J. Geophys. Res., 112, D19 301,doi:10.1029/2006JD008281, 2007.

Jégou, F., Urban, J., de La Noë, J., Ricaud, P., Le Flochmoën, E., Murtagh, D. P., Eriksson, P., Jones, A., Petelina, S., Llewellyn, E. J., Lloyd, N. D., Haley, C., Lumpe, J., Randall, C., Bevilacqua, R. M., Catoire, V., Huret, N., Berthet, G., Renard, J. B., Strong, K., Davies, J., Mc Elroy, C. T., Goutail, F., and Pommereau, J. P.: Technical note: Validation of Odin/SMR limb observations of ozone, comparisons with OSIRIS, POAM III, ground-based and balloon-borne instruments, Atmos. Chem. Phys., 8, 3385-3409, 2008.

Jöckel, P., Sander, R., Kerkweg, A., Tost, H., and Lelieveld, J.: Technical note: The modular earth submodel system (MESSy) a new approach towards Earth System Modeling, Atmos. Chem. Phys., 5, 433-444, 2005.

Jöckel, P., Tost, H., Pozzer, A., Brühl, C., Bucholz, J. L. G., Hoor, P., Kerkweg, A., Lawrence, M., Sander, R., Steil, B., Stiller, G., Tanarhte, M., Taraborelli, D., von Aardenne, J., and Lelieveld, J.: Evaluation of the atmospheric chemistry GCM ECHAM5/MESSy: Consistent simulation of ozone in the stratosphere and troposphere, Atmos. Chem. Phys., 6, 5067-5104, 2006.

Jöckel, P., Kerkweg, A., Buchholz-Dietsch, J., Tost, H., Sander, R., and Pozzer, A.: Technical note: Coupling of chemical processes with the Modular Earth Submodel System (MESSy) submodel TRACER, Atmos. Chem. Phys., 8, 1677-1687, 2008.

Jones, A., Murtagh, D., Urban, J., Eriksson, P., and Rösevall, J.: Intercomparison of Odin/SMR ozone measurements with MIPAS and ballon sonde data, Can. J. Phys., 85, 1111-11 123, 2007.

Kanzawa, H., Schiller, C., Ovarlez, J., Camy-Peyret, C., Payan, 
S., Jeseck, P., Oelhaf, H., Stowasser, M., Traub, W. A., Jucks, K. W., Johnson, D. G., Toon, G. C., Sen, B., Blavier, J.-F., Park, J. H., Bodeker, G. E., Pan, L. L., Sugita, T., Nakajima, H., Yokota, T., Suzuki, M., Shiotani, M., and Sasano, Y.: Validation and data characteristics of water vapor profiles observed by the Improved Limb Atmospheric Spectrometer (ILAS) and processed with the version 5.20 algorithm, J. Geophys. Res., 107, 8217, doi:10.1029/2001JD000 881, (Correction, J. Geophys. Res., 108(D4), 8218, doi:10.1029/20003JD001601, 2003), 2002.

Kelly, K. K., Tuck, A. F., Murphy, D. M., Proffitt, M. H., Fahey, D. W., Jones, R. L., McKenna, D. S., Loewenstein, M., Podolske, J. R., Strahan, S. E., Ferry , K. R. Chan , J. F. Vedder, G. V., Gregory, G. L., Hypes, W. D., McCormick, M. P., Browell, E. V., and Heidt, L. E.: Dehydration in the lower Antarctic stratosphere during late winter and early spring, 1987, J. Geophys. Res., 94, 11317-11357, 1989.

Kerkweg, A., Buchholz, J., Ganzeveld, L., Pozzer, A., Tost, H., and Jöckel, P.: Technical note: An implementation of the dry removal processes DRY DEPosition and sedimentation in the Modular Earth Submodel System (MESSy), Atmos. Chem. Phys., 6, 4617-4632, 2006a.

Kerkweg, A., Sander, R., Tost, H., and Jöckel, P.: Technical note: Implementation of prescribed (OFFLEM), calculated (ONLEM), and pseudo-emissions (TNUDGE) of chemical species in the Modular Earth Submodel System (MESSy), Atmos. Chem. Phys., 6, 3603-3609, 2006 b.

Khosrawi, F., Müller, R., Proffitt, M. H., and Nakajima, H.: Monthly averaged ozone and nitrous oxide from the Improved Limb Atmospheric Spectrometer (ILAS) in the Northern and Southern Hemisphere polar regions, J. Geophys. Res., 109, D10301, doi:10.1029/2003JD004365, 2004.

Khosrawi, F., Müller, R., Proffitt, M. H., and Nakajima, H.: Monthly averages of nitrous oxide and ozone for the Northern and Southern Hemisphere high latitudes: A "1-year climatology" derived from ILAS/ILAS-II observations, J. Geophys. Res., 111, D11S11, doi:10.1029/2005JD006384, 2006.

Khosrawi, F., Müller, R., Proffitt, M. H., Urban, J., Murtagh, D. P., Ruhnke, R., Grooß, J.-U., and Nakajima, H.: The seasonal cycle of averages of nitrous oxide and ozone in the Northern and Southern Hemisphere polar, midlatitude and tropical regions derived from ILAS/ILAS-II and Odin/SMR observations, J. Geophys. Res., 113, D18305, doi:10.1029/2007JD009556., 2008.

Konopka, P., Steinhorst, H.-M., Grooß, J.-U., Günther, G., R., M., Elkins, J. W., Jost, H.-J., Richard, E., Schmidt, U., Toon, G., and McKenna, D. S.: Mixing and ozone loss in the 1999-2000 Arctic vortex: Simulations with the three-dimensional Chemical Lagrangian Model of the Stratosphere CLaMS, J. Geophys. Res., 109, D02315, doi:10.1029/2003JD003792, 2004.

Kouker, W., Langbein, I., Reddmann, T., and Ruhnke, R.: The Karlsruhe Simulation Model of the Middle Atmosphere (KASIMA), Version 2, Tech. rep., Institut für Meteorologie und Klimaforschung, Forschungszentrum Karlsruhe, 1999.

Lambert, A., Read, W. G., Livesey, N. J., Santee, M. L., Manney, G. L., Froidevaux, L., Wu, D. L., Schwartz, M. J., Pumphrey, H. C., Jimenez, C., Nedoluha, G. E., Cofield, R. E., Cuddy, D. T., Daffer, W. H., Drouin, B. J., Fuller, R. A., Jarnot, R. F., Knosp, B. W., Pickett, H. M., Perun, V. S., Snyder, W. V., Stek, P. C., Thurstans, R. P., Wagner, P. A., Waters, J. W., Jucks, K. W., Toon,
G. C., Stachnik, R. A., Bernath, P. F., Boone, C. D., Walker, K. A., Urban, J., Murtagh, D., Elkins, J. W., and Atlas, E.: Validation of the Aura Microwave Limb Sounder middle atmosphere water vapor and nitrous oxide measurements, J. Geophys. Res., 112, D24S36, doi:10.1029/2007JD008724, 2007.

Landgraf, J. and Crutzen, P. J.: An efficient method for online calculations of photolysis and heating rates, J. Atmos. Sci., 55, 863-878, 1998.

Lemmen, C., Dameris, M., Müller, R., and Riese, M.: Chemical ozone loss in a chemistry-climate model from 1960 to 1999 , Geophys. Res. Lett., 33, L15820, doi:10.1029/2006GL026939, 2006.

Llewellyn, E. J., Lloyd, N. D., Degenstein, D. A., Gattinger, R. L., Petelina, S. V., Bourassa, A. E., Wiensz, J. T., Ivanov, E. V., Dade, I. C. M., Solhem, B. H., Connell, J. C. M., Haley, J. C., von Savigny, C., et al.,: The OSIRIS instrument on the Odin spacecraft, Can. J. Phys., 82, 411-422, 2004.

Manney, G. L., Froidevaux, L., Santee, M. L., Livesey, N. J., Sabutis, J. L., and Waters, J. W.: Variability of ozone loss during Arctic winter (1991 to 2000) estimated from UARS Microwave Limb Sounder measurements, J. Geophys. Res., 108, 4149, doi:10.1029/2002JD002634, 2003.

McKenna, D. S., Konopka, P., Grooß, J.-U., Günther, G., Müller, R., Spang, R., Offermann, D., and Orsolini, Y.: A new Chemical Lagrangian Model of the Stratosphere (CLaMS): 1. Formulation of advection and mixing, J. Geophys. Res., 107, 4309, doi:10.1029/2000JD000114, 2002a.

McKenna, D. S., Grooß, J.-U., Günther, G., Konopka, P., Müller, R., Carver, G., and Sasano, Y.: A new Chemical Lagrangian Model of the Stratosphere (CLaMS): 2. Formulation of chemistryscheme and initialisation, J. Geophys. Res., 107, 4265, doi:10.1029/2000JD000113, 2002b.

Michelsen, H. A., Manney, G. L., Gunson, M. R., Rinsland, C. P., and Zander, R.: Correlations of stratospheric abundances of $\mathrm{ch}_{4}$ and $\mathrm{n}_{2} \mathrm{o}$ derived from atmos measurements, Geophys. Res. Lett., 25, 2777-2780, 1998a.

Michelsen, H. A., Manney, G. L., Gunson, M. R., and Zander, R.: Correlations of stratospheric abundances of $\mathrm{NO}_{\mathrm{y}}, \mathrm{O}_{3}, \mathrm{~N}_{2} \mathrm{O}$, and $\mathrm{CH}_{4}$ derived from ATMOS measurements, J. Geophys. Res., 103, 28347-28359, 1998b.

Morcrette, J.-J.: Radiation and cloud radiative properties in the European Centre for Medium Range Weather Forecasts forecasting system, J. Geophys. Res., 96, 9121-9132, 1991.

Müller, R., Crutzen, P. J., Grooß, J.-U., Brühl, C., Russel III, J. M., and Tuck, A. F.: Chlorine activation and ozone depletion in the Arctic vortex: Observations by the Halogen Occultation Experiment on the Upper Atmosphere Research Satellite, J. Geophys. Res., 101, 12531-12554, 1996.

Müller, R., Grooß, J.-U., McKenna, D., Crutzen, P. J., Brühl, C., Russell, J. M., and Tuck, A. F.: HALOE observations of the vertical structure of chemical ozone depletion in the Arctic vortex during winter and early spring 1996-1997, Geophys. Res. Lett., 24, 2717-2720, 1997.

Müller, R., Schmidt, U., Engel, A., McKenna, D., and Proffitt, M.: The $\mathrm{O}_{3} / \mathrm{N}_{2} \mathrm{O}$ relationship from balloon-borne observations as a measure of Arctic ozone loss in 1991-1992, Q. J. Roy. Meteor. Soc., 127, 1389-1412, 2001.

Müller, R., Tilmes, S., Konopka, P., Grooß, J.-U., and Jost, H.-J.: Impact of mixing and chemical change on ozone-tracer relations 
in the polar vortex, Atmos. Chem. Phys., 5, 3139-3151, 2005.

Müller, R., Grooß, J.-U., Lemmen, C., Heintze, D., Dameris, M., and Bodeker, G.: Simple measures of ozone depletion in the polar stratosphere, Atmos. Chem. Phys., 8, 253-267, 2008.

Murtagh, D., Frisk, U., Merino, F., Ridal, M., Jonsson, A., Stegman, J., Witt, G., Eriksson, P., Jimenez, C., and et al.: An overview of the Odin atmospheric mission, Can. J. Phys., 80, 309-319, 2002.

Nakajima, H., Sugita, T., Irie, H., Saitoh, N., Oelhaf, H., Wetzel, G., Toon, G. C., Sen, B., Traub, W. A., Jucks, K., Yokota, T., and Sasano, Y.: Measurements of $\mathrm{ClONO}_{2}$ by the Improved Limb Atmospheric Spectrometer (ILAS) in high latitude stratosphere: New products of version 6.1 data processing, J. Geophys. Res., 111, D11S09, doi:10.1029/2005JD006441, 2006a.

Nakajima, H., Sugita, T., Yokota, T., Kobayashi, H., Sasano, Y., Ishigaki, T., Mogi, Y., Araki, N., Waragai, N., Kumura, N., Iwasawa, T., Kuze, T., Tanii, J., Togami, T., Kawasaki, H., Horikawa, M., and Uemura, N.: Characteristics and performance of the Improved Limb Atmospheric Spectrometer-II (ILAS-II) on board the ADEOS-II satellite, J. Geophys. Res., 111, D11S01, doi:10.1029/2005JD006334, 2006b.

Oshchepkov, S., Sasano, Y., Yokota, T., Uemura, N., Matsuda, H., Itou, Y., and Nakajima, H.: Simultaneous stratospheric gas and aerosol retrievals from broadband infrared occulation measurements, Appl. Opt., 22, 4775-4784, 2005.

Plumb, R. A.: Tracer interrelationships in the stratosphere, Rev. Geophys., 45, doi:10.1029/2005RG000179, 2007.

Plumb, R. A. and Ko, M. K. W.: Interrelationships between mixing ratios of long-lived stratospheric constituents, J. Geophys. Res., 97, 10145-10156, 1992.

Proffitt, M. H., Fahey, D., Kelly, K., and Tuck, A.: High latitude ozone loss outside the Antarctic ozone hole, Nature, 342, 233 237, 1989a.

Proffitt, M. H., Kelly, K. K., Powell, J. A., Gary, B. L., Loewenstein, M., Podolske, J. R., Strahan, S. E., and Chan, K. R.: Evidence of diabatic cooling and poleward transport within and around the 1987 Antarctic Ozone Hole, J. Geophys. Res., 94, 1679716813, 1989b.

Proffitt, M. H., Margitan, J. J., Kelly, K. K., Loewenstein, M., Podolske, J. R., and Chan, K. R.: Ozone loss in the Arctic polar vortex inferred from high altitude aircraft measurements, Nature, 347, 31-36, 1990.

Proffitt, M. H., Aikin, K., Margitan, J. J., Loewenstein, M., Podolske, J. R., Weaver, A., Chan, K. R., Fast, H., and Elkins, J. W.: Ozone loss inside the northern polar vortex during the 1991-1992 winter, Science, 261, 1150-1154, 1993.

Proffitt, M. H., Aikin, K., Tuck, A. F., Margitan, J. J., Webster, C. R., Toon, G. C., and Elkins, J. W.: Seasonally averaged ozone and nitrous oxide in the Northern Hemisphere lower stratosphere, J. Geophys. Res., 108(D3), 4110, doi:10.1029/2002JD002657, 2003.

Randel, W. J., Gille, J. C., Roche, A. E., Kumer, J. B., Mergenthaler, J. L., Waters, J. W., Fishbein, E. F., and Lahoz, W. A.: Stratospheric transport from the tropics to middle latitudes by planetary-wave mixing, Nature, 365, 533-535, 1993.

Reddmann, T., Ruhnke, R., and Kouker, W.: Three-dimensional model simulations of $\mathrm{SF}_{6}$ with mesospheric chemistry, J. Geophys. Res., 106, 14525-14537, 2001.

Rex, M., Salawitch, R., Toon, G., Sen, B., Margitan, J., Osterman,
G., Blavier, J.-F., Gao, R., Donnelly, S., Keim, E., Neumann, J., Fahey, D., Webster, C., Scott, D., Herman, R., May, R., Moyer, E., Gunson, M., Irion, F., Chang, A., Rinsland, C., and Bui, T. Subsidence, mixing and denitrification of Arctic polar vortex air measured during POLARIS, J. Geophys. Res., 104, 2661126623, 1999.

Roeckner, E., Brokopf, R., Esch, M., Giorgetta, M., Hagemann, S., Koernblueh, L., Manzini, E., Schlese, U., and Schulzweida, U.: Sensitivity of simulated climate to horizontal and vertical resolution in the ECHAM5 atmosphere model, J. Climate, 19, 3771-3791, 2006.

Rosenfield, J. E., Newman, P. A., and Schoeberl, M. R.: Computations of diabatic descent in the stratospheric polar vortex, J. Geophys. Res., 99, 16677-16689, 1994.

Rothman, L. S., Barbe, A., Benner, D. C., Brown, L. R., CamyPeyret, C., Carleer, M. R., Chance, K., Clerbaux, C., Dana, V., Devi, V. M., Fayt, A., Flaud, J.-M., Gamache, R. R., Goldman, A., Jaquemart, D., Jucks, K. W., Lafferty, W. J., Mandin, J.-Y., Massie, S. T., Nemtchinov, V., Newnham, D. A., Perrin, A., Rinsland, C. P., Schroeder, J., Smith, K. M., Smith, M. A. H., Tang, K., Roth, R. A., Auwera, J. V., Varanasi, P., and Yoshino, K.: The HITRAN molecular spectroscopic database: Edition of 2000 including updates through 2001, J. Quant. Spectrosc. Rad. T., 82, 5-44, 2003.

Rothman, L. S., Jaquemart, D., Barbe, A., Benner, D. C., Birk, M., Brown, L. R., Carleer, M. R., Jr., C. C., Chance, K., Coudert, L., Dana, V., Devi, V. M., Flaud, J.-M., Gamache, R. R., Goldman, A., Hartmann, J.-M., Jucks, K. W., Maki, A. G., Mandin, J.Y., Massie, S. T., Orphal, J., Perrin, A., Rinsland, C. P., Smith, M. A. H., Tennyson, J., Tolchenov, R. N., Toth, R. A., Auwera, J. V., Varanasi, P., and Wagner, G.: The HITRAN 2004 molecular spectroscopic database, J. Quant. Spectrosc. Rad. T., 96, 139204, 2005.

Ruhnke, R., Kouker, W., and Reddmann, T.: The influence of the $\mathrm{OH}+\mathrm{NO}_{2}+\mathrm{M}$ reaction on the $\mathrm{NO}_{\mathrm{y}}$ partitioning in the late Arctic winter 1992/1993 as studied with KASIMA, J. Geophys. Res., 104, 3755-3772, 1999.

Russell, J. M., Tuck, A. F., Gordley, L. L., Park, J. H., Drayson, S. R., Harries, J. E., Cicerone, R. J., and Crutzen, P. J.: HALOE Antarctic observations in spring 1991, Geophys. Res. Lett., 20, 719-722, 1993.

Salawitch, R., Margitan, J., Sen, B., Toon, G., Osterman, G., Rex, M., Elkins, J., Ray, E., Moore, F., Hurst, D., Romashkin, P., Bevilacqua, R., Hoppel, K., Richard, E., and Bui, T.: Chemical loss of ozone during the Arctic winter of 1999-2000: An analysis based on balloon-borne observations, J. Geophys. Res., 107 , 8269, doi:10.1029/2001JD000 620, 2002.

Sander, R., Kerkweg, A., Jöckel, P., and Lelieveld, J.: Technical note: The new comprehensive atmospheric chemistry module MECCA, Atmos. Chem. Phys., 5, 445-450, 2005.

Sander, S. P., Friedl, R. R., Ravishankara, A. R., Golden, D. M., Kolb, C. E., Kurylo, M. J., Huie, R. E., Orkin, V. L., Molina, M. J., Moortgat, G. K., and Finnlaysen-Pitts, B. J.: Chemical kinetics and photochemical data for the use in atmospheric studies, Evaluation Number 14, JPL Publication 02-25, 2003.

Sankey, D. and Shepherd, T. G.: Correlation of long-lived chemical species in a middle atmosphere general circulation model, J. Geophys. Res., 108, 4494, doi:10.1029/2002JD002799, 2003.

Sasano, Y., Suzuki, M., Yokota, T., and Kanzawa, H.: Improved 
Limb Atmospheric Spectrometer (ILAS) for stratospheric ozone layer measurements by solar occultation technique, Geophys. Res. Lett., 26, 197-200, 1999.

Shaw, T. and Shepherd, T. G., Raising the roof, Nature Geoscience, 1, 12-13, 2008.

Strong, K., Wolff, M. A., Kerzenmacher, T. E., Walker, K. A., Bernath, P. F., Blumenstock, T., Boone, C., Catoire, V., Coffey, M., De Mazière, M., Demoulin, P., Duchatelet, P., Dupuy, E., Hannigan, J., Höpfner, M., Glatthor, N., Griffith, D. W. T., Jin, J. J., Jones, N., Jucks, K., Kuelmmann, H., Kuttipurath, J., Lambert, A., Mathieu, E., McConnell, J. C., Mellquist, J., Mikuteit, S., Murtagh, D. P., Notholt, J., Piccolo, C., Raspollini, P., Ridolfi, M., Robert, C., Schneider, M., Schrems, O., Semeniuk, K., Senten, C., Stiller, G. P., Strandberg, A., Taylor, J., Tétard, C., Toohey, M., Urban, J., Warneke, T., and Wood, S.: Validation of ACE-FTS $\mathrm{N}_{2} \mathrm{O}$ measurements, Atmos. Chem. Phys., 8, 47594786, 2008

Sugita, T., Yokota, T., Nakajima, H., Kanzawa, H., Nakane, H., H.Gernandt, Yushkov, V., Shibasaki, K., Deshler, T., Kondo, Y., Godin, S., Goutail, F., Pommereau, J. P., Camy-Peret, C., Payan, S., Jeseck, P., Renard, J.-B., Bösch, H., Fitzenberger, R., Pfeilsticker, K., von König, M., Bremer, H., Küllmann, H., Schlager, H., Margitan, J. J., Stachnik, B., Toon, G. C., Jucks, K., Traub, W. A., Johnson, D. G., Murata, I., Fukunishi, H., and Sasano, Y.: Validation of ozone measurements from the Improved Limb Atmospheric Spectrometer (ILAS), J. Geophys. Res., 107, 8212, doi:10.1029/2001JD000602, 2002.

Sugita, T., Nakajima, H., Yokota, T., Kanzawa, H., Gernandt, H., Herber, A., van den Gathen, P., Koenig-Langlo, G., K.Sato, Dorokhov, V., Yushukov, V. A., Murayama, Y., Yamamori, M., Godin-Beekmann, S., et al.: A comparative study of ozone profiles in the stratosphere and the lower mesosphere measured by the Improved Limb Atmospheric Spectrometer (ILAS-II), ozonsondes, and satellite profiles, J. Geophys. Res., 111, D11S02, doi:10.1029/2005JD006439, 2006.

Tanaka, T., Nakajima, H., Sugita, T., Ejiri, M. K., Irie, H., Saitoh, N., Terao, Y., Kawasaki, H., Usami, M., Kawasaki, H., Yokota, T., Kobayashi, H., and Sasano, Y.: Tangent height registration method for the Version 1.4 data retrieval algorithm of the solar occultation sensor ILAS-II, Appl. Optics, 46, 7196-7201, 2007.

Tilmes, S., Müller, R., Grooß, J.-U., McKenna, D. S., Russell, J. M., and Sasano, Y.: Calculation of chemical ozone loss in the Arctic winter 1996-1997 using ozone-tracer correlations: Comparison of Improved Limb Atmospheric Spectrometer (ILAS) and Halogen Occultation (HALOE) results, J. Geophys. Res., 108, 4045, doi:10.1029/2002JD002213, 2003.

Tilmes, S., Müller, R., Grooß, J.-U., and Russell, J. M.: Ozone loss and chlorine activation in the Arctic winters 1991-2003 derived with the tracer-tracer correlations, Atmos. Chem. Phys., 4, 2181-2213, 2004.

Tilmes, S., Müller, R., Grooß, J.-U., Spang, R., Nakajima, H., and Sasano, Y.: Chemical ozone loss and related processes in the Antarctic winter 2003 based on ILAS-II observations, J. Geophys. Res., 111, D11S12, doi:10.1029/2005JD006260, 2006.

Tilmes, S., Kinnison, D., Müller, R., Sassi, F., Marsh, D. R., Boville, B. A., and Garcia, R.: Evaluation of heterogeneous processes in the polar lower stratosphere in WACCM3, J. Geophys. Res., 112, D24302, doi:10.1029/2006JD008334, 2007.

Tilmes, S., Garcia, R. R., Kinnision, D. E., Gettelmann, A., and Rasch, P.: Impact of geo-engineered aerosols on the troposphere and stratosphere, J. Geophys. Res., 114, D12305, doi:10.1029/2008JD011420, 2009.

Tost, H., Jöckel, P., Kerkweg, A., Sander, R., and Lelieveld, J.: Technical note: A new comprehensive scavenging submodel for global atmospheric chemistry modelling, Atmos. Chem. Phys., 6, 565-574, 2006a.

Tost, H., Jöckel, P., and Lelieveld, J.: Influence of different convection parameterisations in a GCM, Atmos. Chem. Phys., 6, 5475-5493, 2006b.

Tost, H., Jöckel, P., Kerkweg, A., Pozzer, A., Sander, R., and Lelieveld, J.: Global cloud and precipitation chemistry and wet deposition: tropospheric model simulations with ECHAM5/MESSy1, Atmos. Chem. Phys., 7, 2733-2757, 2007a.

Tost, H., Jöckel, P., and Lelieveld, J.: Lightning and convection parameterisations - uncertainties in global modelling, Atmos. Chem. Phys., 7, 4553-4568, $2007 \mathrm{~b}$.

Tuck, A. F.: Synoptic and chemical evolution of the Antarctic vortex in late winter and early spring, 1987, J. Geophys. Res., 94, 11687-11737, 1989.

Tuck, A. F. and Proffitt, M. H.: Comment on "On the magnitude of transport out of the Antarctic polar vortex" written by: Wauben, W. M. F., Bitanja, R., van Velthoven, P. J. F., and Kelder, H., J. Geophys. Res., 102, 28215-28218, 1997.

Tuck, A. F., Watson, R. T., Condon, E. P., Margitan, J. J., and Toon, O. B.: The planning and execution of ER-2 and DC-8 aircraft flights over Antarctica, August and September 1987, J. Geophys. Res., 94, 11181-11222, 1989.

Urban, J., Lautié, N., Le Flochmoën, E., Jiménez, C., Eriksson, P., De La Noë, J., Dupuy, E., Ekström, M., El Amraoui, L., Frisk, U., Murtagh, D., Olberg, M., and Ricaud, P.: Odin/SMR limb observations of stratospheric trace gases: Level 2 processing of $\mathrm{ClO}, \mathrm{N}_{2} \mathrm{O}, \mathrm{HNO}_{3}$, and $\mathrm{O}_{3}$, J. Geophys. Res., 110, D14 307,doi:10.1029/2005JD005 741, 2005a.

Urban, J., Lautié, N., Le Flochmoën, E., Jiménez, C., P.Eriksson, De La Noë, J., Dupuy, E., El Amraoui, L., Frisk, U., Jégou, F., Murtagh, D., Olberg, M., Ricaud, P., Camy-Peyret, C., Dufour, G., Payan, S., Huret, N., Pirre, M., Robinson, A. D., Harris, N. R. P., Bremer, H., Kleinböhl, A., Küllmann, K., Künzi, K., Kuttipurath, J., Ejiri, M. K., Nakajima, H., Sasano, Y., Sugita, T., Yokota, T., Piccolo, C., Raspollini, P., and Ridolfi, M.: Odin/SMR limb observations of stratospheric trace gases: Validation of $\mathrm{N}_{2} \mathrm{O}$, J. Geophys. Res., 110, D09301, doi:10.1029/2005JD005394, 2005b.

Urban, J., Murtagh, D., Lautié, N., Barret, B., Dupuy, E., De La Noë, J., Eriksson, P., Frisk, U., Jones, A., Le Flochmoën, E., Olberg, M., Piccolo, C., Ricaud, P., and Rösevall, J.: Odin/SMR limb observations of trace gases in the polar lower stratosphere during 2004-2005, in Proceedings of the ESA First Atmospheric Science Conference, 8-12 May 2006, Frascati, Italy, edited by: Lacoste, H., Eur. Space Agency Spec. Publ., 2006.

Wetzel, G., Sugita, T., Nakajima, H., Tanaka, T., Yokota, T., FriedlVallon, F., Kleinert, A., Maucher, G., and Oelhaf, H.: Technical Note: Intercomparison of ILAS-II Version 2 and 1.4 trace species with MIPAS-B measurements, Atmos. Chem. Phys., 8, 11191126, 2008.

WMO, Scientific assessment of ozone depletion: 2006, Report No. 50, Geneva, 2007 
Yokota, T., Nakajima, H., Sugita, T., Tsubaki, H., Itou, Y., Kaji, M., Suzuki, M., Kanzawa, H., Park, J. H., and Sasano, Y.: Improved Limb Atmospheric Spectrometer (ILAS) data retrieval algorithm for Version 5.20 gas profile products, J. Geophys. Res., 107, 8216, doi:10.1029/2001JD000628, 2002. 